NBER WORKING PAPER SERIES

INFORMATION AND MULTI-PERIOD

OPTIMAL INCOME TAXATION

WITH GOVERNMENT COMMITMENT

\author{
Dagobert L. Brito
}

Jonathan H. Hamilton

Steven M. Slutsky

Joseph E. Stiglitz

Working Paper No. 2458

\author{
NATIONAL BUREAU OF ECONOMIC RESEARCH \\ 1050 Massachusetts Avenue \\ Cambridge, MA 02138 \\ December 1987
}

The research reported here is part of the NBER's research program in Taxation. Any opinions expressed are those of the authors and not those of the National Bureau of Economic Research. 
NBER Working Paper \#2458

December 1987

\section{Information and Multi-Period Optimal Income \\ Taxation with Government Commitment}

\section{$\underline{\text { ABSTRACT }}$}

The optimal income taxation problem has been extensively studied in oneperiod models. When consumers work for many periods, this paper analyzes what information, if any, that the government learns about abilities in one period can be used in later periods to attain more redistribution than in a oneperiod world. When the government must cammit itself to future tax schedules, the gains come from relaxing self-selection constraints by intertemporal nonstationarity. The effect of nonstationarity is analogous to that of randomization in one-period models.

In a model with two ability classes it is shown that the key use of information is that only a single lifetime self-selection constraint for each type of consumer must be imposed. Some necessary and sufficient conditions for randomization or nonstationarity are given. The plamner can make additional use of the information when individual and social rates of time discounting differ. In this case, the limiting tax schedule is a nondistorting one if the government has a lower discount rate than individuals.

Dagobert L. Brito

Department of Economics

Rice University

Houston, TX 77251

Steven M. Slutsky Department of Economics University of Florida

Gainesville, FL 32611
Jonathan H. Hamilton

Department of Economics

University of Florida

Gainesville, FL 32611

Joseph E. Stiglitz

Department of Economics

Princeton University

Princeton, NJ 08544 


\section{Introduction}

Most optimal income tax models in the Mirrlees [1971] tradition analyze only a single period. If individuals are identifiable across periods, questions arise about the contimued validity of the results in those models. An obvious objection is that, in the first period, the govermment learns individuals' abilities and therefore should be able to attain a first best result in the next period. If individuals do not recognize that their second period taxes depend upon their first period behavior, this conclusion is correct. However, if individuals correctly anticipate this linkage and adjust their behavior accordingly, the gain from using the information is at least partially negated. This paper considers whether the first best outcome can be achieved in later periods despite this response by individuals and if not, whether the use of any information from period one can lead to an improvement over simple repetition of the one period optimal tax schedule.

The model has individuals of two discrete ability classes. The government knows the size and ability level of each class but does not initially know to which class any particular individual belongs. This paper thus adapts the one perind model of Stiglitz [1982a] to a many period situation and relaxes assumptions about the preferences of the two classes.

Two different assumptions about the government's use of information can be made. One is that the government is able to commit itself to the tax schedules it will use in each period and thus to limit the extent to which it uses information about an individual's ability, learned from the taxes paid in one period, to affect the taxes paid in later periods. The other is that the government camnot cammit itself in advance not to use infonmation to the full extent. Once an individual's ability is learned, the government is not only able to impose lump sum taxation but does so as soon as possible. Both assumptions are worth studying. The second may be more realistic since it may 
in fact be impossible for governments to comit themselves even by constitutional means since later governments can change rules and constitutions. On the other hand, the no commitment solution is feasible when camitment is possible but not the reverse. Hence, the first assumption allows studying a benchmark case where information is used optimally across periods. In this paper, the first assumption of comitment is made. Elsewhere, we malyze the no commitment case.

When the goverment can comit itself, the following results are shown:

(1) If first best is not optimal in a one period model, it is not optimal in later periods of a milti-period model.

(2) The self-selection constraint creates a potential nonconvexity which implies that sometimes it may be desirable to have different tax functions in each period.

(3) When the tax structure differs between periods, the information from the first period incorporated in later periods' schedules is only an individual's ability class. The plamer uses this to incorporate a large penalty in later periods for an agent who acts in the second period as if his ability differs from that revealed in the first, thus forcing agents to be consistent in their behavior across periods.

These results follow from noting that a multiperiod optimal tax model and a one period model with random taxation as discussed in Stiglitz [1982a] are essentially the same. The random tax model has no restrictions on the relative frequencies with which different schedules are offered. With an infinite horizon, it is possible to exactly duplicate the random solution. However, in a finite period model, restrictions exist on the frequency with which bundles can be offered over time. In addition, the multiperiod model may be more restrictive if it has period-by-period government budget constraints instead of one intertemporal constraint. Despite these extra 
restrictions, similar arguments show that different tax schecules in different periods may be desirable. Intertemporal nonstationarity is an alternative method of implementing random taxes that does not require either ex ante or ex post violations of horizontal equity.

(4) The "single crossing" assumption cammon to many self-selection models is not needed for most results. At the optimum, at most one selfselection constraint can bind whether or not single crossing is assumed. A complete characterization of the solution to the one-period problem, with and without random taxation, is given both in terms of taxes and the Pareto frontier. These results are more general than previous analyses since no specific relationship between the classes is assumed.

(5) When a self-selection constraint binds, randomization is desirable for any indifference map under a sufficiently concave transformation of the utility function of the class with the binding constraint. If a local randomization improves upon the nonrandom solution, then for any three probabilities, some lottery with those probabilities improves upon the nonrandom solution.

In section II, the basic model is described and results for a one period model with and without randomization are derived. In addition, more general conditions are derived for randomization to be desirable than have previously appeared in the literature. In section III, the multiperiod problem is considered. Results are given for a single intertemporal government budget constraint and for separate period-by-period constraints. The results depend upon whether the govermment's and individuals' discount rates differ. If they are equal, information is used across periods only to mimic randomization. When they differ, systematic use of information occurs since "trade" between the government and individuals is now possible due to different discount rates. In section $\mathrm{IV}$, some general conclusions are drawn about the use of information in optimal tax models. 


\section{Taxation in a One Period Model}

In this section, we analyze the basic one period model. The results here generalize those in Stiglitz [1982a] and help draw the analogy between random taxation and multiperiod taxation.

\section{A. Basic Assumptions}

A society is composed of two different classes of individuals denoted A and $B$. The individuals within each class are identical but the two classes differ either in tastes or abilities. The goverment is assumed initially not to know to which class any individual belongs but to know the mmbers of individuals in each class, denoted $N_{i}, i=a, b$. Individuals consume a single good, $C$, and earn income, $Y$. People in each class have a utility function over these bundles $V^{i}(C, Y), i=a, b$, with $\partial V^{i} / \partial C \equiv v_{c}^{i}>0$ and $\partial V^{i} / \partial Y \equiv v_{y}^{i}<0$. The maximm income that individuals in each class can earn is bounded from above by $K^{i}$ so that $Y^{i} \leq K^{i}, i=a, b$. The marginal rate of substitution for a given individual is denoted $\operatorname{MRS}^{i}(C, Y) \equiv-v_{y}^{i} / v_{c}^{i}>0, i=a, b$.

The following assumptions are made about $\mathrm{V}^{i}(C, Y)$ :

(Al) $V^{i}(C, Y), i=a, b$, is twice contimously differentiable in $C$ and $Y$;

(A2) $V^{i}(C, Y), i=a, b$, is strictly concave in $C$ and $Y$;

(A3) $\operatorname{MRS}^{\mathrm{a}}(\mathrm{C}, \mathrm{Y})$ and $\mathrm{MRS}^{\mathrm{b}}(\mathrm{C}, \mathrm{Y})$ differ at almost every (C, Y) bundle and points where the MRS's are equal are not where the indifference curves are tangent to the no-tax budget line.

Assumption (AI) is made for convenience but could be relaxed without difficulty. Assumption (A2) of concavity (instead of quasiconcavity) insures that expected utility in the random taxation model and lifetime discounted utility in multiperiod models describe convex preferences. Assumption (A3) is crucial in guaranteeing that the two groups actually have different preferences since, if their indifference curves coincide, redistribution between groups is 
impossible. Assumption (A3) allows the indifference curves of the two classes to have multiple crossings. If there are multiple crossings, then there will be bundles at which the indifference curves of the two groups are tangent, having equal marginal rates of substitution. Such tangencies are not ruled out as long as they form discrete lines in the (C, Y) plane. ${ }^{1}$

A special case satisfying these assumptions is that considered in Stiglitz [1982a] in which the utility functions $V^{i}(C, Y)$ arise from common underlying preferences over consumption and labor with the classes A and B having different abilities (and wages). Let $L^{i}$ be hours worked and $w_{i}$ the wage rate of group $i$. Then $L^{i}=Y / w_{i}$ and $V^{i}(C, Y)=U\left(C, Y / w_{i}\right)$ where $U$ is the common utility function over $C$ and $L$. If $A$ is the more able group $\left(w_{a}>w_{b}\right)$ then $\operatorname{MRS}^{\mathrm{a}}(\mathrm{C}, \mathrm{Y})<\mathrm{MRS}^{\mathrm{b}}(\mathrm{C}, \mathrm{Y})$ at each (C, Y). ${ }^{2}$ As shown below, such a "single crossing" assumption is umecessary for most of the standard results.

\section{B. Nonrandom Taxation}

Assume that the government must impose the same tax on everyone who earns the same income either to satisfy horizontal equity or for administrative ease. It camot randomly charge some individuals a different tax than others. Since the government camnot distinguish individuals of the two classes, it must therefore offer a single tax schedule $\mathrm{T}(\mathrm{Y})$ to all individuals. ${ }^{3}$ An individual belonging to either class then faces a budget constraint $C \leqq Y-T(Y)$ and maximizes utility subject to this constraint taking the tax schedule as given. For each possible tax schedule, there will be a best consumption-income vector $\left(C^{i}(T), Y^{i}(T)\right)$ for each class and a utility for each class $v^{i T}=V^{i}\left(C^{i}(T)\right.$, $\left.Y^{i}(T)\right)$. It is clear that for any $T, V^{i T} \geq V^{i}\left(C^{j}(T), Y^{j}(T)\right), i \neq j$, since $V^{i T}$ is the maximm given the constraint and $\left(C^{j}(T), Y^{j}(T)\right)$ is a feasible vector for both classes. ${ }^{4}$ Budget balance, $\mathrm{N}_{a} T\left(Y^{\mathrm{a}}\right)+\mathrm{N}_{b} \mathrm{~T}\left(\mathrm{Y}^{\mathrm{b}}\right) \geq 0$, must also be satisfied for feasibility. ${ }^{5}$ The government then seeks the tax function which yields the 
"best" pair of utilities $\left(\mathrm{V}^{\mathrm{aT}}, \mathrm{V}^{\mathrm{bT}}\right)$. This best pair could be selected according to a social welfare function. For any social welfare function, the pair $\left(V^{a T}\right.$, $v^{b T}$ ) will be a constrained Pareto optimm. Thus, in this paper, we consider the set of Pareto-optimal utilities without arbitrarily assuming a particular welfare function.

Since directly searching over tax functions to find the optimm is difficult, an equivalent problem is solved of choosing $\left(C^{i}, Y^{i}\right)$ pairs for each class that satisfy self-selection constraints, $V^{i}\left(C^{i}, Y^{i}\right) \geq V^{i}\left(C^{j}, Y^{j}\right), i=a$ and $b$ and $j \neq i$. That is, individuals in neither class can prefer the bundle assigned to the other class to their own. These self-selection constraints are necessary and sufficient for there to exist a tax function under which the two classes optimally choose the assigned bundles. Necessity was argued above. To show sufficiency, note that if $\mathrm{Y}^{i} \geq \mathrm{Y}^{j}$ then $\mathrm{C}^{\mathrm{i}}>\mathrm{C}^{j}$ must also hold or both classes prefer $\left(\mathrm{C}^{j}, \mathrm{Y}^{\mathrm{j}}\right)$. Consider the tax function,

$$
T(Y)=Y, Y<Y^{j}, T(Y)=Y-C^{j}, Y^{j} \leq Y<Y^{i}, T(Y)=Y-C^{i}, Y^{i} \leq Y .
$$

Under this step function, the only bundles which individuals in either class could choose are $(0,0),\left(C^{j}, Y^{j}\right)$, and $\left(C^{i}, Y^{i}\right)$. This follows, for example, since $\left(C^{i}, Y^{i}\right)$ is preferred to any bundle $\left(C^{i}, Y\right), Y>Y^{i}$, which are the only ones possible for incomes greater than $\mathrm{Y}^{i}$. In addition, under boundary conditions on preferences, either bundle will be preferred to $(0,0)$. Under this tax function, individuals in class $i$ can do no better than $\left(C^{i}, Y^{i}\right)$ and those in $\mathrm{j}$ can do no better than $\left(\mathrm{C}^{\mathrm{j}}, \mathrm{Y}^{\mathrm{j}}\right){ }^{6}$ Given the individuals' budget constraints, budget balance is satisfied if $N_{a}\left(C^{a}-Y^{a}\right)+N_{b}\left(C^{b}-Y^{b}\right) \leq 0$ (aggregate consumption no greater than aggregate income).

The government's one period norrandom Pareto taxation problem then can be written as maximization problem (PI) ${ }^{7}$ 
(PI) $\operatorname{Max} \quad{ }_{a N} V_{a} V^{a}\left(C^{a}, Y^{a}\right)+(1-a) N_{b} v^{b}\left(C^{b}, Y^{b}\right)$

$$
\begin{array}{ll}
\text { s.t. } & V^{i}\left(C^{i}, Y^{i}\right) \geq V^{i}\left(C^{j}, Y^{j}\right), i=a, b, j \neq i: \lambda_{i} \\
& N_{a}\left(C^{a}-Y^{a}\right)+N_{a}\left(C^{b}-Y^{b}\right) \leq 0 \quad: \mu \\
& 0 \leqq Y^{i} \leq K^{i}, i=a, b \\
& C^{i} \geq 0, i=a, b
\end{array}
$$

where $\alpha$ is a parameter which can be varied between 0 and 1 to find the constrained Pareto frontier, $\lambda_{i}, i=a, b$, is the Lagrange multiplier associated with the self-selection constraint of class $i$; and $\mu$ is the Lagrange multiplier associated with the resource balance constraint.

Theorem I: For all $a \in[0,1]$, there exists a solution $\left(\left(C^{a^{*}}, \mathrm{Y}^{\mathrm{a}^{*}}\right),\left(\mathrm{C}^{\mathrm{b}^{*}}, \mathrm{Y}^{\mathrm{b}^{*}}\right)\right)$ to maximization problem (PI).

Proof: The constraint set is nonempty since any $Y^{a}=Y^{b}=C^{a}=C^{b} \leqq \min \left(K^{a}, K^{b}\right)$ satisfies all the constraints in (PI). The constraint set is closed because all constraint functions are contimuous in the choice variables and the constraints are specified by weak inequalities. Incomes are bounded by assumption and these bounds imply that consumptions are bounded through the resource constraint. Hence, the constraint set is boumded. The objective function is contimuous and thus attains a maximum on the nonempty compact constraint set.

To characterize the solution to (PI), let $\mathrm{C}^{i}(\alpha), \mathrm{Y}^{i}(\alpha)$, and $V^{i}(\alpha) \equiv V^{i}\left(C^{i}(\alpha), Y^{i}(\alpha)\right), i=a, b$, be the optimal bundles and utilities as functions of $\alpha$. Let $v^{i o}, i=a, b$, be the utilities of each group in the no tax situation.

Theorem II: The solution to (PI) satisfies the following properties: (i) If $V^{i}(\alpha) \geq V^{i o}$ then $V^{i}\left(c^{j}(\alpha), Y^{j}(\alpha)\right)<V^{i}(\alpha), i=a, b$ and $j \neq i$. 
(ii) If $\mathrm{V}^{i}(\alpha)=\mathrm{V}^{i}\left(\mathrm{C}^{j}(\alpha), \mathrm{Y}^{j}(\alpha)\right)$ then $\mathrm{V}^{j}(\alpha)>\mathrm{V}^{j}\left(\mathrm{C}^{\mathrm{i}}(\alpha), \mathrm{Y}^{\mathrm{i}}(\alpha)\right), i=a, b$ and $j \neq i$.

(iii) $\mu>0$

(iv) If $\lambda_{i}=0$ then $\operatorname{MRS}^{j}\left(C^{j}(\alpha), \mathrm{Y}^{j}(\alpha)\right)=1, i=a, b$ and $j \neq i$.

(v) If $\lambda_{i}>0$ then for $i=a, b$ and $j \neq i$ either

$$
\begin{aligned}
& 1<\operatorname{MRS}^{j}\left(C^{j}(\alpha), Y^{j}(\alpha)\right)<\operatorname{MRS}^{i}\left(C^{j}(\alpha), Y^{j}(\alpha)\right) \text {, or } \\
& \operatorname{MRS}^{i}\left(C^{j}(\alpha), Y^{j}(\alpha)\right)<\operatorname{MRS}^{j}\left(C^{j}(\alpha), Y^{j}(\alpha)\right)<1 .
\end{aligned}
$$

Before proving Theorem II, an explanation of these conditions is in order. The first says that the self-selection constraint does not bind for a group which receives higher utility than in the no-tax situation. The second says that at most one self-selection constraint can bind at the optimm -- even with multiple crossings of the indifference curves. The third says that production efficiency is satisfied in that all production is consumed $\left(\mathrm{N}_{a}\left(C^{a}-\right.\right.$ $\left.\left.Y^{a}\right)+N_{b}\left(C^{b}-Y^{b}\right)=0\right)$. The fourth says that, if the self-selection constraint does not bind for group $i$, then the optimm bundle for the group $j$ is one with no distortion -- the implicit marginal tax rate is zero. The fifth condition says that if the self-selection constraint for group $i$ is binding, then at group $j$ 's bundle, $\mathbf{M R S}^{j}$ lies between the marginal rate of transformation and $\mathrm{MRS}^{i}$. The marginal rate of transformation $(=1)$ can be either larger or smaller than the two MRS's.

\section{Proof:}

(i) Consider the no tax situation. The budget constraint of group $i$ is $C^{i} \leq Y^{i}$ and the optimal choice $\left(C^{i o}, Y^{i o}\right)$ satisfies $C^{i o}=Y^{i o}$ from monotonicity of $V^{i}\left(C^{i}, Y^{i}\right)$. If $V^{i}\left(C^{j}, Y^{j}\right)=V^{i}\left(C^{i}, Y^{i}\right) \geq v^{i o}$, then $C^{i} \geq Y^{i}$ and $C^{j} \geq Y^{j}$ must hold with strict inequality in the second unless $\left(C^{j}, Y^{j}\right)=$ $\left(C^{i}, Y^{i}\right)=\left(C^{i o}, Y^{i o}\right)$. This latter possibility can occur only when 
$V^{i}\left(C^{i}, Y^{i}\right)=V^{\text {io }}$ and $M R S^{i}\left(C^{i o}, Y^{i o}\right)=M S^{j}\left(C^{i o}, Y^{i o}\right)=1$. Disregarding this special case, $N_{i}\left(C^{i}-Y^{i}\right)+N_{j}\left(C^{j}-Y^{j}\right)>0$ must hold, violating the resource balance constraint. (See Figure 1).

(ii) The no tax utilities $\left(\mathrm{V}^{\mathrm{ao}}, \mathrm{v}^{\mathrm{bo}}\right)$ are feasible and must lie on the constrained Pareto frontier. It is impossible to raise both types' welfare since no distortions exist. There must exist some $\alpha_{0}$ for which $v^{i}\left(\alpha_{0}\right)=v^{i o}$, $i=a, b$. Hence, for any other $\alpha$, either $V^{a}(\alpha) \geq V^{a}\left(\alpha_{0}\right)$ or $V^{b}(\alpha) \geq V^{b}\left(\alpha_{0}\right)$. From (i), the group whose utility is at least at the no tax level camnot have its self-selection constraint bind. It is thus impossible to have selfselection constraints binding for both groups.

(iii) Rewrite the resource constraint as $N_{a}\left(C^{a}-Y^{a}\right)+N_{b}\left(C^{b}-Y^{b}\right) \leq \gamma$ and let $L(\alpha, \gamma)$ be the value of the objective function of (PI) at the optimm. Then, from the envelope theorem, differentiating $L$ around $\gamma=0, \partial L / \partial \gamma=\mu$. For any $\gamma>0$, the extra resources can always be given to the groups whose self-selection constraint is not binding without any of the constraints being violated. This raises the value of the objective fumction, showing $\partial L / \partial \gamma>0.8$

(iv) Assume $\lambda_{i}=0$ and the self-selection constraint for group $i$ holds with strict inequality. If $\operatorname{MRS}^{\mathrm{j}}\left(\mathrm{C}^{\mathrm{j}}(\alpha), \mathrm{Y}^{\mathrm{j}}(\alpha)\right)>1$, then, for small $\delta$, $\mathrm{V}^{j}\left(\mathrm{C}^{\mathrm{j}}(\alpha)-\delta, \mathrm{Y}^{\mathrm{j}}(\alpha)-\delta\right)>\mathrm{V}^{\mathrm{j}}\left(\mathrm{C}^{\mathrm{j}}(\alpha), \mathrm{Y}^{\mathrm{j}}(\alpha)\right)$ and $\mathrm{V}^{\mathrm{i}}\left(\mathrm{C}^{\mathrm{j}}(\alpha)-\delta, \mathrm{Y}^{\mathrm{j}}(\alpha)-\delta\right)<\mathrm{V}^{\mathrm{i}}(\alpha)$ will hold. Since resource balance continues to hold, the bundle $\left(C^{j}(\alpha)-\delta\right.$, $\left.\mathrm{Y}^{j}(\alpha)-\delta\right)$ yields a higher value for the objective function. Similarly, if $\operatorname{MRS}^{\mathbf{j}}\left(C^{j}(\alpha), Y^{j}(\alpha)\right)<1,\left(C^{j}(\alpha)+\delta, Y^{j}(\alpha)+\delta\right)$ yields a higher value of the objective function. (See Figure 2). If $\lambda_{i}=0$ but the self-selection constraint holds with equality, then from (ii), $\lambda_{j}=0$ must hold. The first order conditions immediately yield the result since terms from neither self-selection constraint enter. 
$\operatorname{MRS}^{j}\left(C^{\tilde{j}}(\alpha), Y^{j}(\alpha)\right)<1,\left(C^{j}(\alpha)+\delta, Y^{j}(\alpha)+\delta\right)$ yields a higher value of the objective function. (See figure 2). If $\lambda_{i}=0$ but the self-selection constraint holds with equality, then from (ii), $\lambda_{j}=0$ must hold. The first order conditions immediately yield the result since terms from neither self-selection constraint enter.

(v) Assume $\lambda_{a}>0$ so that from (ii), $\lambda_{b}=0$ must hold. The first order conditions with respect to $C^{\mathrm{b}}$ and $\mathrm{Y}^{\mathrm{b}}$ are:

$$
\begin{aligned}
& (1-\alpha) N_{b} V_{c}^{b}\left(C^{b}, Y^{b}\right)-\lambda_{a} V_{c}^{a}\left(C^{b}, Y^{b}\right)-\mu N_{b}=0 \\
& (1-\alpha) N_{b} V_{y}^{b}\left(C^{b}, Y^{b}\right)-\lambda_{a} V_{y}^{a}\left(C^{b}, Y^{b}\right)+\mu N_{b}=0
\end{aligned}
$$

Solving for $\mathrm{uN}_{\mathrm{b}}$ and combining terms yields:

$$
(I-\alpha) N_{b}\left[V_{c}^{b}\left(C^{b}, Y^{b}\right)+V_{y}^{b}\left(C^{b}, Y^{b}\right)\right]=\lambda_{a}\left[V_{c}^{a}\left(C^{b}, Y^{b}\right)+V_{y}^{a}\left(C^{b}, Y^{b}\right)\right]
$$

or:

$$
(1-\alpha) N_{b} V_{c}^{b}\left(C^{b}, Y^{b}\right)\left[1-M_{R}^{b}\left(C^{b}, Y^{b}\right)\right]=\lambda_{a} V_{c}^{a}\left(C^{b}, Y^{b}\right)\left[1-M_{R}^{a}\left(C^{b}, Y^{b}\right)\right]
$$

Adding $\lambda_{a} V_{c}^{a}\left(C^{b}, Y^{b}\right) M R S^{b}\left(C^{b}, Y^{b}\right)$ to both sides of (4), combining terms, and substituting (1) yields

$$
{ }_{\mu} N_{b}\left[1-M R S^{b}\left(C^{b}, Y^{b}\right)\right]=\lambda_{a} V_{c}^{a}\left(C^{b}, Y^{b}\right)\left[M R S^{b}\left(C^{b}, Y^{b}\right)-M R S^{a}\left(C^{b}, Y^{b}\right)\right]
$$

Since $\lambda_{a}$ (by assumption) and $\mu$ (from part (ii)) are positive, the result follows.

If $\lambda_{b}>0$, similar manipulation of the first order conditions for $C^{a}$ and $Y^{a}$ shows the required results.

Q.E.D. 
Requiring taxes to raise net revenue does not change significantly any of the results. In Theorem II(i), instead of using the no tax situation as a benchmark, the situation with a lump sum tax equal to the per capita share of net required revenue can be used and all the results follow.

(2) If the "single crossing" assumption is made, as in Stiglitz [1982a] due to different abilities, MRS ${ }^{a}<M^{b} S^{b}$ holds at all $(C, Y)$ bundles. Thus, part (v) simplifies to $\lambda_{a}>0$ implies $\mathbb{M R S}^{a}\left(C^{b}(\alpha), Y^{b}(\alpha)\right)<\mathbb{M R S}^{b}\left(C^{b}(\alpha), Y^{b}(\alpha)\right)<1$ and $\lambda_{b}>0$ implies $\left.1<\operatorname{MRS}^{a}\left(C^{a}(\alpha)\right), Y^{a}(\alpha)\right)<\operatorname{MRS}^{b}\left(C^{a}(\alpha), Y^{a}(\alpha)\right)$.

(3) The intuition behind part (v) can be given by argiments similar to the proof of part (iv). Assume $\lambda_{a}>0$ and that $\mathbb{M R S}^{\mathrm{b}}\left(\mathrm{C}^{\mathrm{b}}, \mathrm{Y}^{\mathrm{b}}\right)<1<\operatorname{MRS}^{\mathrm{a}}\left(\mathrm{C}^{\mathrm{b}}, \mathrm{Y}^{\mathrm{b}}\right)$. Then, at least for small $\delta>0$, if the bundle $\left(C^{b}, Y^{b}\right)$ is changed to $\left(c^{b}+\delta, Y^{b}+\delta\right)$ resource balance continues to be satisfied. A's selfselection constraint holds with strict inequality, and B's welfare rises yielding a Pareto improvement. (See Figure 3). If $\operatorname{MRS}^{\mathrm{b}}\left(\mathrm{C}^{\mathrm{b}}, \mathrm{Y}^{\mathrm{b}}\right)<\mathbb{M R S}^{\mathrm{a}}\left(\mathrm{C}^{\mathrm{b}}, \mathrm{Y}^{\mathrm{b}}\right.$ ) $<1$ or if $1<M_{R}^{a}\left(C^{b}, Y^{b}\right)<M^{b}\left(C^{b}, Y^{b}\right)$, then moving $\left(C^{b}, Y^{b}\right)$ along $A^{\prime} s$ indifference curve below the $45^{\circ}$ line through $\left(C^{b}, Y^{b}\right)$ leaves the selfselection constraint for A holding with equality, raises B's utility, and yields extra resources which can be given to A to yield a Pareto improvement. (See Figrre 4).

(4) Along the Pareto frontier, there are regions in which each selfselection constraint binds. Even if the two groups differ only because of ability differences, it cannot be assumed that the self-selection constraint of the able will bind. At same points on the frontier, little redistribution is done and neither binds. At others, the redistribution is from the unable to the able, so the self-selection constraint of the unable binds.

(5) Our characterization of the optimal taxes permits comparisons between the utility possibility frontiers (UPF) of the constrained problem and the full 
information problem (with no self-selection constraints). If neither selfselection constraint binds, then the two UPF's coincide. If one binds, then the constrained UPF lies strictly below the full-information one. With the additional assumption that consumption and leisure are normal for both classes, the three regions of the UPF (neither constraint binds, the constraint on A binds, the constraint on B binds) are comected segments. (See Figure 5).

Corollary I: Under assumptions (Al)-(A3) and normality of consumption and leisure, if a self-selection constraint binds at a point on the UPF then that constraint binds at all points on the UPF with lower utility for that class. The UPF has three segments: first, one self-selection constraint binds; then, neither binds (this includes the no-tax point); lastly, the other selfselection constraint binds.

Proof: Consider a solution to (PI) for some $\alpha$ such that $\lambda_{a}>0$. Denote this solution as $\left(C_{1}^{a}, Y_{1}^{a}, C_{1}^{b}, Y_{1}^{b}\right)$ where $V^{a}\left(C_{1}^{a}, Y_{1}^{a}\right)=V^{a}\left(C_{1}^{b}, Y_{1}^{b}\right)$ and, from Theorem II (i), $V^{a}\left(C_{1}^{a}, Y_{1}^{a}\right)<v^{a o}$. From Theorem I(v), $\operatorname{Mrs}^{b}\left(C_{1}^{b}, Y_{1}^{b}\right) \neq 1$. Let $\left(C_{3}^{b}, Y_{3}^{b}\right)$ be the bundle such that $V^{b}\left(C_{3}^{b}, Y_{3}^{b}\right)=V^{b}\left(c_{1}^{b}, Y_{1}^{b}\right)$ and $M^{b}\left(c_{1}^{b}, Y_{1}^{b}\right)=1$. Then $\left(C_{3}^{b}, Y_{3}^{b}\right)$ is the bundle which minimizes $C^{b}-Y^{b}$ subject to $V^{b}\left(c^{b}, Y^{b}\right)=V^{b}\left(C_{1}^{b}, v_{1}^{b}\right)$. From strict concavity, it then follows that $c_{3}^{b}-Y_{3}^{b}<C_{1}^{b}-Y_{I}^{b}$. Therefore, $V^{a}\left(c_{2}^{b}, Y_{2}^{b}\right)>V^{a}\left(c_{1}^{b}, Y_{1}^{b}\right)$ must hold. If not, and $V^{a}\left(c_{3}^{b}, Y_{3}^{b}\right) \leq V^{a}\left(c_{1}^{b}, Y_{1}^{b}\right)$, then the bundle $\left(C_{1}^{a}, Y_{1}^{a}, C_{3}^{b}, Y_{3}^{b}\right)$ would satisfy self-selection for both types and, as compared to $\left(C_{1}^{a}, Y_{1}^{a}, C_{1}^{b}, Y_{1}^{b}\right)$ would give both types the same utility but would use less net resources. This would contradict the assumption that $\left(C_{1}^{a}, Y_{1}^{a}, C_{1}^{b}, Y_{1}^{b}\right)$ is on the constrained UPF.

Assume that the result is false so that there exists a solution for some other $a,\left(C_{2}^{a}, Y_{2}^{a}, C_{2}^{b}, Y_{2}^{b}\right)$ which is on the constrained UPF at a lower utility for $A$ and at wich neither self-selection constraint binds. That is, assume (i) 
$V^{a}\left(C_{1}^{b}, Y_{1}^{b}\right)=V^{a}\left(C_{1}^{a}, Y_{1}^{a}\right)>V^{a}\left(C_{2}^{a}, Y_{2}^{a}\right) \geq V^{a}\left(c_{2}^{b}, Y_{2}^{b}\right)$, (ii) $V^{b}\left(C_{2}^{b}, Y_{2}^{b}\right)>V^{b}\left(C_{1}^{b}, Y_{1}^{b}\right)$, and (iii) $\operatorname{MRS}^{a}\left(C_{2}^{a}, Y_{2}^{a}\right)=\operatorname{MRS}^{b}\left(C_{2}^{b}, Y_{2}^{b}\right)=1$. From these assumptions, it follows that $\mathrm{C}_{2}^{\mathrm{b}} \geq \mathrm{C}_{3}^{\mathrm{b}}$ and $\mathrm{Y}_{2}^{\mathrm{b}} \geq \mathrm{Y}_{3}^{\mathrm{b}}$ cammot both hold. If both held, then $V^{\mathrm{a}}\left(\mathrm{C}_{2}^{\mathrm{b}}, \mathrm{Y}_{2}^{\mathrm{b}}\right) \geq$ $V^{a}\left(c_{3}^{b}, Y_{3}^{b}\right)$ and hence, since $V^{a}\left(c_{3}^{b}, Y_{3}^{b}\right)>V^{a}\left(c_{1}^{b}, Y_{1}^{b}\right)$ was shown above, $V^{a}\left(c_{2}^{b}, Y_{2}^{b}\right)>$ $V^{a}\left(C_{1}^{b}, Y_{1}^{b}\right)$ which contradicts (i). Therefore, either $C_{3}^{b}<C_{2}^{b}$ or $Y_{3}^{b}>Y_{2}^{b}$ must hold. Since, from (ii) and (iii), $\operatorname{MRS}^{\mathrm{b}}\left(\mathrm{C}_{2}^{\mathrm{b}}, \mathrm{Y}_{2}^{\mathrm{b}}\right)=\mathrm{MRS}^{\mathrm{b}}\left(\mathrm{C}_{3}^{\mathrm{b}}, \mathrm{Y}_{3}^{\mathrm{b}}\right)$ and $\mathrm{V}^{\mathrm{b}}\left(\mathrm{C}_{3}^{\mathrm{b}}, \mathrm{Y}_{3}^{\mathrm{b}}\right)<$ $\mathrm{V}^{\mathrm{b}}\left(\mathrm{C}_{3}^{\mathrm{b}}, \mathrm{Y}_{2}^{\mathrm{b}}\right)$, the first inequality would imply that consumption is inferior and the second that leisure is inferior. In either case, a contradiction arises from assuming the result is false.

(6) In the constrained problem, the self-selection constraints imply minimm utility levels for each group, while in the full information problem, utility for a group can be pushed down to $v^{i}\left(0, K^{i}\right)$. Thus the utility possibility frontier is truncated at higher utility levels. For example, suppose the classes differ only in ability with $w_{a}>w_{b}$. For any $Y>0$, $V^{a}(C, Y)>V^{b}(C, Y)$ since $A^{\prime} s$ need to work less to earn the same income. $V^{a}\left(C^{a}, Y^{a}\right)>V^{b}\left(C^{b}, Y^{b}\right)$ since $V^{a}\left(C^{a}, Y^{a}\right) \leq V^{b}\left(C^{b}, Y^{b}\right)<V^{a}\left(C^{b}, Y^{b}\right)$ violates A's self-selection constraint. Thus, A must always achieve more utility than B. This remains true if the problem is formulated as maximizing $v^{i}$ subject to $\mathrm{V}^{j}$ being not less than a target level, and varying the target to map out the utility possibility frontier. At low enough target levels, the target constraint will not bind.

(7) The ordering of MRS's at the distorted bundle, $\left(\mathrm{C}^{j}, \mathrm{Y}^{j}\right)$ if $\lambda_{i}>0$, has an interpretation in terms of taxes. If the group desiring to mimic (i) has the steeper indifference curve through $j$ 's bundle, then group $j$ is subsidized on the margin. If $i$ has the flatter indifference curve through $j$ 's bundle, group $j$ is taxed on the margin. 


\section{B. Random Taxation}

The desirability of randomization in optimal taxation models, or in principal-agent models in general, has been studied by Weiss [1976], Stiglitz [1982a], Fellingham, Kwon, and Newman [1984], and Arnott and Stiglitz [1985]. (A related problem is that of designing auctions; Maskin and Riley [1984] have established the desirability of randamization of payoffs in optimal auctions.) The results in this section generalize those in Stiglitz [1982a]. The random action by the goverment takes place after individuals reveal their type but before they decide their levels of effort. The goverment constructs two lotteries of tax schedules, one intended for individuals in group A and one for those in group B. Each individual must decide which lottery to participate in. Then, at random, a tax schedule is assigned to the individual. The individual, given his tax schedule, decides on the amount of income to produce. Since the individual has already declared his type, every schedule can be constructed to allow only one $(\mathrm{C}, \mathrm{Y})$ bundle to be chosen, even if the individual has misrevealed his type. Thus, each lottery can be viewed as a lottery over different ( $C, Y$ ) bundles - one for each possible tax schedule that may be drawn.

Randomization before the effort decision cannot do worse than randomization after the effort decision. Assume the randomization occurs after the effort decision. In all outcomes, the individual produces the same pre-tax income but consumption differs depending upon the tax charged. Thus, at the revelation stage, each lottery can be viewed as over (C, Y) bundles in which $Y$ is fixed and $C$ differs. Such lotteries remain feasible when the income decision is made after randomization but, in that case, other bundles with different $Y$ 's also are feasible. Hence, randomization after the income decision, yields a smaller feasible set for the government and may be suboptimal. 9 
On the other hand, randomization before revelation camot improve on randomization after revelation. In such circumstances, the government randomly assigns tax schedules to individuals without knowing their type. After receiving a schedule, an individual faces no further uncertainty. Each schedule the government randomizes over can be treated as a pair of (C, Y) bundles, one for each type. When the government's problem is transformed to choosing pairs of $(\mathrm{C}, \mathrm{Y})$ bundles, then each pair corresponding to one tax schecule must satisfy the self-selection constraints for each type. When the randomization occurs after revelation, only one self-selection constraint over the expected utilities arises. Although the bundles under prerevelation randomess will satisfy this expected constraint, it is clearly weaker and hence the prerevelation randomess may be suboptimal. 10

To specify formally the government's optimization with the possibility of random taxation, consider the lotteries to be offered to the two groups $A$ and B. Each group will be offered a set of bundles and a probability for each bundle in the set. The lotteries thus are $L^{i}\left(\left(C^{i h}, Y^{i h}\right), \pi_{i h}\right), i=a, b$, and $h=1, \ldots, k(i)$ where $k(i)$ is some finite number. The government can choose both the bundles and the probabilities in each lottery. The one period maximization problem with randomization (PII) is then:

(PII) Max $\quad \alpha N_{a} \sum_{h=1}^{k(a)} \pi a h^{a}\left(C^{a h}, Y^{a h}\right)+(1-\alpha) N_{b} \sum_{h=1}^{k(b)} \pi_{b h} v^{b}\left(c^{b h}, Y^{b h}\right)$

$$
\begin{aligned}
& \text { st. } \sum_{h=1}^{k(i)} \pi_{i h} v^{i}\left(C^{i h}, Y^{i h}\right) \geq \sum_{h=1}^{k(j)} \pi j v^{i}\left(c^{j h}, Y^{j h}\right) \quad i=a, b, j=i: \hat{\lambda}_{i} \\
& N_{a} \sum_{h=1}^{\left.k \int a\right)} \pi_{a h}\left(C^{a h}-Y^{a h}\right)+N_{b} \sum_{h=1}^{k(b)} \pi_{b h}\left(c^{b h}-Y^{b h}\right) \leq 0: \hat{\mu}
\end{aligned}
$$




$$
\begin{aligned}
& \sum_{h=1}^{k(i)} \pi_{i h}=1, i=a, b, \quad \pi_{i h} \geq 0, i=a, b \text { and } h=1, \ldots, k(i) \\
& 0 \leqq Y^{i h} \leqq k^{i}, i=a, b, h=1, \ldots, k(i) \\
& 0 \leqq c^{i h} \leqq M^{i}, i=a, b, h=1, \ldots, k(i)
\end{aligned}
$$

As in (PI), $\alpha$ is a weight which can be varied to find the entire Pareto frontier, $\hat{\lambda}_{i}$ and $\hat{\mu}$ are the multipliers on the self-selection and resource constraints. The upper bounds $M^{i}$ on $C^{\text {ih }}$ bound the feasible set. ${ }^{11}$

In problem (PII), the objective function and constraints incorporate ex ante expected values. For the self-selection constraints and the government's objective function this is reasonable. The government must design the tax scheme and the individuals must decide which type to declare before realization. It is therefore of no consequence if, ex post, someone prefers the bundle achieved by someone of the other type. However, production occurs after the realization of the random process. If the ex post realization has total consumption greater than income, it is not feasible even though expected consumption equaled expected income. For the constraints in (PII), this can clearly occur. If some $\mathrm{C}^{\text {ih }}$ exceeds $\mathrm{N}_{\mathrm{a}} \mathrm{K}^{\mathrm{a}}+\mathrm{N}_{\mathrm{b}} \mathrm{K}^{\mathrm{b}}$ (maximm total production), even if it arises with very small probability, the outcome is not feasible when this bundle arises. Such ex post violations of feasibility can clearly occur even if the $\mathrm{M}^{\mathrm{i}}$ are set to restrict all $\mathrm{C}^{\mathrm{ih}}$ to be less than $\mathrm{N}_{\mathrm{a}} \mathrm{K}^{\mathrm{a}}+\mathrm{N}_{\mathrm{b}} \mathrm{K}^{\mathrm{b}} \cdot 12$

One justification for the constraint is if the government places one tax function for each individual of a particular type into an urn and the individuals draw without replacement. Then the ex ante expected net resource use of an individual is achieved exactly ex post by the group. Hence the constraint in (PII) is appropriate. An altemative justification of the constraint in (PII) is that each individual of a revealed typed draws a tax schedule at random from the same distribution. As the number of individuals 
gets large, the distribution of ex post resource balance will always have values violating the constraint. However, the law of large numbers implies that the per capita violation of the constraint goes to zero. Thus if the consumption vectors are reduced by even an arbitrarily small $\varepsilon$, the probability that the constraint is satisfied goes to 1 as the population grows. Hence, the solution to (PII) can be viewed as an $\varepsilon$-equilibrium in this case. Since the self-selection constraints holding with equality already imply that the solution to (PII) is an $\varepsilon$-equilibrium, this is not a real restriction.

To summarize, there exist randomization procedures under which the resource constraint in (PII) is appropriate. Without specifying it in detail, such a procechre is assumed to be utilized by the government. Care must be taken, since for other procedures, the formulation in (PII) is inappropriate. Under allowable procedures, a solution to (PII) always exists.

Theorem III: For every $\alpha$, there exists a pair of lotteries $\mathrm{L}^{\mathrm{a}^{*}}\left(\left(\mathrm{C}^{\mathrm{ah}}, \mathrm{Y}^{\mathrm{ah}}\right)\right.$, $\left.\pi_{a h}^{*}\right), h=1, \ldots k^{*}(a)$ and $L^{b^{*}}\left(\left(c^{b h^{*}}, Y^{b h^{*}}\right), \pi_{b h}^{*}\right), h=1, \ldots, k^{*}(b)$ which solve (PII). Proof: As in Theorem I, the constraint set is nonempty since feasible bundles in (PI) can be treated as degenerate lotteries. The constraint set is closed and all variables $\left(\pi_{i h}, C^{i h}, Y^{i h}\right.$ ) are bounded. Hence, the constraint set is compact. The contimuous objective function then attains a maximm on the nonempty compact constraint set.

The optimal lotteries which solve (PII) can be characterized in a similar manner to the nonrandom optimm. As in the previous section, $v^{i o}, i=a, b$, are the utilities in the no tax situation, $\left(\left(C^{i h}(\alpha), Y^{i h}(\alpha)\right), \pi_{i h}(\alpha)\right)$, $i=a, b, h=1, \ldots, k^{*}(i)$, are the optimal lotteries as a function of $\alpha$, and $\mathrm{EV}^{i}(\alpha) \equiv \sum_{h=1}^{k^{*}(i)} \pi_{i h}(\alpha) V^{i}\left(C^{i h}(\alpha), Y^{i h}(\alpha)\right), i=a, b$, are the optimal expected utilities achieved as functions of $\alpha$. 
Theorem IV: The solution to (PII) satisfies the following properties

If $\operatorname{EV}^{i}(\alpha) \geq V^{i o}$ then $\sum_{h=1}^{k(j)} \pi_{j h}(\alpha) V^{i}\left(C^{j h}(\alpha), Y^{j h}(\alpha)\right)<\operatorname{EV}^{i}(\alpha), i=a, b$, $j \neq i$.

(ii) If $\operatorname{EV}^{i}(\alpha)=\sum_{h=1}^{k(j)} \pi j h(\alpha) V^{i}\left(C^{j h}(\alpha), Y^{j h}(\alpha)\right)$ then $\operatorname{EV}^{j}(\alpha)>$

$$
\sum_{h=1}^{k(i)} \pi i h(\alpha) V^{j}\left(C^{i h}(\alpha), Y^{i h}(\alpha)\right), i=a, b, \text { and } j \neq i \text {. }
$$

(iii) $\hat{\mu}>0$.

(iv) If $i$ 's self-selection constraint does not bind, then an optimal solution exists with $k(j)=1$ and $\operatorname{MRS}^{j}\left(C^{j 1}(\alpha), Y^{j 1}(\alpha)\right)=1, i=a, b$, and $j \neq i$.

(v) For $i=a, b$, and $j \neq i$, if $\lambda_{i}>0$ then an optimal solution exists with $k(j) \leq 3$ and at each $h=1, \ldots, k(j)$, either

$$
\begin{aligned}
& 1<\operatorname{MRS}^{j}\left(C^{j h}(\alpha), Y^{j h}(\alpha)\right)<\operatorname{MRS}^{i}\left(C^{j h}(\alpha), Y^{j h}(\alpha)\right), \\
& \operatorname{MRS}^{i}\left(C^{j h}(\alpha), Y^{j h}(\alpha)\right)<\operatorname{MRS}^{j}\left(C^{j h}(\alpha), Y^{j h}(\alpha)\right)<1 \text {, or } \\
& \operatorname{MRS}^{i}\left(C^{j h}(\alpha), Y^{j h}(\alpha)\right)=\operatorname{MRS}^{j}\left(C^{j h}(\alpha), Y^{j h}(\alpha)\right)=1 .
\end{aligned}
$$

Proof: See the Appendix.

Conditions (i)-(iii) of Theorem IV are essentially the same as those of Theorem II with the utilities replaced by expected utilities. Condition (iv) states that if the self-selection constraint of group $i$ is not binding then it is desirable to have no randomization for group $j$ and, as in Theorem II, there is no distortionary taxation at this bundle. Condition (v) states that there is no gain to having randomization over more than three bundles and, if randomization is over group $j$ 's bundles, then at each of those bundles the $\mathrm{MRS}^{i}, \mathrm{MRS}^{j}$ and $\operatorname{MRT}(=1)$ must relate to each other in the ways specified in condition ( $v$ ) of Theorem II. That is, at each $\left(C^{j h}, Y^{j h}\right), M^{j} S^{j}$ must lie between $\mathbb{R S}^{i}$ and 1 . The 
possibility that $\mathbb{M R S}^{i}=\mathbb{M R S}^{j}=1$ at one of the bundles camot be ruled out. Note it is possible to randomize with $\mathrm{MRS}^{i}$ and $\mathrm{MRS}^{j}$ greater than 1 at some bundles and less than 1 at others. Single crossing imposes the same relation between $\mathrm{MRS}^{\mathrm{i}}$ and $\mathrm{MRS}^{\mathrm{j}}$ at all bundles in the lottery.

In the solution to (PII), at most one nondegenerate lottery is needed and randamization over more than three bundles is umecessary. It has not been shown that either group will face a nondegenerate lottery. First order conditions are of little use for showing that a nondegenerate lottery exists or for finding the random solution, because the nonrandom solution to (PI) satisfies the first order conditions for (PII). To see this, denote the nomrandom solution as a lottery over $k(i)$ bundles where each bundle is identical to the nonrandom bundle solving (PI). First order conditions with respect to $\pi_{\text {in }}$ are trivially satisfied and those with respect to $C^{\text {ih }}$ and $Y^{\text {ih }}$ reduce to those in (PI). Hence, a nondegenerate randan solution exists only when multiple solutions to the first order conditions exist, with the extra solutions asymetric (and not readily apparent). However, since the self-selection constraints involve the difference in utilities and therefore do not define convex sets, multiple solutions are possible. Theorem $V$ shows that for any pair of indifference maps satisfying assumptions (AI)-(AIII), some allowable transformation exists under which a randam solution is desirable. Maskin and Riley [1980] show a similar result with a continum of abilities for the special case of preferences which are additive in consumption and labor and linear in consumption.

Theorem V: Consider any $V^{i}$ and $V^{j}$ satisfying assumption (A1)-(A3) and any $\alpha$ such that $\lambda_{i}>0, i=a, b$. Then there exists some concavification of $v^{i}$ such that $k(j)>1$ holds in the solution to (PII), whether or not $v^{j}$ is similarly transformed. Proof: See the Appendix. 
In Theorem $V$, only the utility function of individuals in group $i$ is transformed. However, transforming the utility of individuals in group $j$ as well does not change the result since the randomization involves bundles over which $j$ is indifferent. Hence, the result also applies to situations in which the two groups have the same utility functions but differ in ability. See Figure 6 for an illustration of the construction.

The construction in the proof demonstrates clearly how the nonconvexity of the self-selection constraints can induce randomization. If group $j$ has the random bundle, then the transformation makes group $i$ 's utility function more concave and thus reduces the desirability of $j$ 's lottery to individuals in group $i$. This weakens $i$ 's self-selection constraint and allows for adjustments which raise $j$ 's expected utility. Having the initial randomization over two bundles which are chosen to be indifferent to the optimum nonrandom bundle given to $\mathrm{j}$ is a convenient way to demonstrate that an improvement over the solution in (PI) exists. This particular randomization has a special property -- it does not violate horizontal equity defined as identical agents having equal utilities even if they have different budget sets. All type j's receive equal utility, although with different consumption bundles. The randomization only causes utilities to be stochastic for type $i$ 's who mimic type j's. While this may not be the optimal randomization, it remains feasible even when ex post horizontal equity is required.

Theorem $\mathrm{V}$ shows that the desirability of randomization cannot be ruled out from indifference maps since randomization can arise for essentially any indifference maps under some transformation. It is worth noting however, that the shape of the indifference map does have some effect on whether randamization is desirable. The next theorem gives a necessary and sufficient condition for local randomization which depends in part on the curvature of 
indifference curves. Assume $\lambda_{a}>0$ in the solution to (PI) so that the marginal tax rate is not zero at $\left(C^{b}, Y^{b}\right)$. Let $H^{i}$ be the Hessian of the utility function of type $i$ at $\left(C^{b}, Y^{b}\right)$.

Theorem VI: Assume $\lambda_{a}>0$ in the solution to (PI) and consider any probability triple $\left(\pi_{1}, \pi_{2}, \pi_{3}\right)$, at least two of which are positive and $\Pi_{1}+\pi_{2}+\Pi_{3}=1$. There exists some local randomization with these probabilities around the nonrandom solution to (PI) which improves on that solution iff there exists $q \varepsilon \mathrm{R}^{2}$ such that

$$
\frac{q^{b} q^{t}}{V_{c}^{b}\left(C^{b}, Y^{b}\right)\left|1-M S^{b}\left(C^{b}, Y^{b}\right)\right|}>\frac{q^{a} q^{t}}{V_{c}^{a}\left(C^{b}, Y^{b}\right)\left|1-M R S^{a}\left(C^{b}, Y^{b}\right)\right|}
$$

where $q^{t}$ is the transpose of $q$. Proof: See the Appendix

The expression in (6) depends upon properties of the indifference map though the $\mathrm{MRS}^{i}\left(\mathrm{C}^{\mathrm{b}}, \mathrm{Y}^{\mathrm{b}}\right)$ terms and the $\mathrm{qH}^{\mathrm{i}} \mathrm{q}^{\mathrm{t}}$ terms which depend upon both the curvature of indifference curves and the transformation of utility.

As a corollary, it follows that, if preferences of A's and B's are similar, then local randomization will not be desirable. Assume the utility functions belong to a family parameterized by $P, V^{a}\left(C, Y, P_{a}\right)$ and $\left(V^{b}\left(C, Y, P_{b}\right)\right.$. Corollary II: Assume that preferences are related such that at all $\mathrm{P}=\mathrm{P}_{\mathrm{a}}=\mathrm{P}_{\mathrm{b}}$, $V^{a}(C, Y, P)=F\left(V^{b}(C, Y, P)\right)$. Then, for $P_{a}$ near $P_{b}$, no randomization is desirable unless F is sufficiently concave. Proof: See the Appendix.

A special case of this result is two classes with identical preferences but different abilities. If the abilities are close to each other, no randomization is desirable regardless of which group the redistribution favors. ${ }^{13}$ Both Theorem V and Corollary II show that concavifying utility. 
makes randomization desirable. Theorem $\mathrm{V}$ concerns the degree of concavity of each utility function separately, while Corollary II involves the concavity of one utility function relative to the other. For $P_{a}$ near $P_{b}$, if both functions undergo the same transformation, no local randomization will be desirable. Theorem $\mathrm{V}$ demonstrates that, if $\mathrm{P}_{\mathrm{a}} \neq \mathrm{P}_{\mathrm{b}}$, randomization will be desirable if the common transformation is extreme enough. Thus, this randomization must be a nonlocal randomization of bundles offered a group in a lottery.

In order to see that the condition of Theorem VI can be satisfied, consider a special case of all individuals having identical additive utility functions over consumption and labor with the groups differing only in ability.

Corollary III: Consider the utility functions $v^{i}(C, Y)=\psi(C)-\gamma\left(Y / w_{i}\right)$, $i=a, b$, where the $w_{i}$ are ability parameters with $0<w_{b}<w_{a}$. To satisfy concavity of $v^{i}, \psi$ is concave and $\gamma$ convex. Let $L^{i}=Y / w_{i}$.

(A) Assume the self-selection constraint for group A is binding.

(i) No randomization is desirable if $\mathrm{L} \gamma^{\prime \prime \prime}(\mathrm{L}) / \mathrm{\gamma}^{\prime \prime}(\mathrm{L}) \geq-2$, at all $\mathrm{L}$.

(ii) Consider any probabilities $\left(\pi_{1}, \pi_{2}, \pi_{3}\right)$ with at least two positive and with $\pi_{1}+\pi_{2}+\pi_{3}=1$. There exists some local randomization with these probabilities around the nowrandom optimm of (PI) which improves on the nonrandam solution iff:

$$
\frac{\gamma^{\prime \prime}\left(Y^{b} / w_{a}\right)}{w_{a}{ }^{2}\left(1-M R S^{a}\left(C^{b}, Y^{b}\right)\right)}>\frac{r^{\prime \prime}\left(Y^{b} / w_{b}\right)}{w_{b}{ }^{2}\left(1-M R S^{b}\left(C^{b}, Y^{b}\right)\right)}
$$

(B) Assume the self-selection constraint for group $B$ is binding:

(i) No randamization is desirable if $L \gamma^{\prime \prime \prime}(\mathrm{L}) / \gamma^{\prime \prime}(\mathrm{L}) \leq-2$, at all $\mathrm{L}$.

(ii) Consider any probabilities $\left(\pi_{1}, \pi_{2}, \pi_{3}\right)$ with at least two positive and with $\pi_{1}+\pi_{2}+\pi_{3}=1$. There exists some local randamization with these probabilities around the nonrandam optimm of (PI) which improves on the nonrandom solution iff: 


$$
\frac{r^{\prime \prime}\left(Y^{a} / w_{b}\right)}{w_{b}^{2}\left(M R S^{b}\left(C^{a}, Y^{a}\right)-1\right)}>\frac{r^{\prime \prime}\left(Y^{a} / w_{a}\right)}{w_{a}^{2}\left(M R S^{a}\left(C^{a}, Y^{a}\right)-1\right)}
$$

Proof: See the Appendix.

Consider the condition in $A(i i)$. Since $w_{a}>w_{b}$ and $1-M S^{a}\left(C^{b}, Y^{b}\right)>$ $1-M_{R S}^{b}\left(C^{b}, Y^{b}\right)>0$, the denominator of the LHS exceeds that of the RHS in (7). Hence, $\gamma^{\prime \prime}\left(Y^{b} / w_{a}\right)$ must exceed $\gamma^{\prime \prime}\left(Y^{b} / w_{b}\right)$ by a sufficient amount for this condition to be satisfied. Since $\mathrm{Y}^{\mathrm{b}} / \mathrm{w}_{\mathrm{a}}<\mathrm{Y}^{\mathrm{b}} / \mathrm{w}_{\mathrm{b}}$, this can be satisfied by $a$ sufficiently negative value of $\gamma^{\prime \prime}$. A sufficient condition for (7) to be satisfied is that the derivative of $\gamma^{\prime \prime}(Y / w) /\left[w^{2}(1-M R S)\right]$ with respect to $w$ be positive. Taking this derivative yields the following sufficient condition for the desirability of local randomization with any probabilities which is stricter than the necessary condition in $A(i)$ of Theorem VI:

$$
\mathrm{L}^{\prime}{ }^{\prime \prime}(\mathrm{L}) / \gamma^{\prime \prime}(\mathrm{L})<-2-\left[\gamma^{\prime}(\mathrm{L})+\gamma^{\prime \prime}(\mathrm{L})\right] /\left[\mathrm{w} \psi^{\prime}(\mathrm{C})-\gamma^{\prime}(\mathrm{L})\right]
$$

where $w \psi^{\prime}(C)-\gamma^{\prime}(L)=w \psi^{\prime}(C)\left(1-\operatorname{MRS}\left(C^{b}, Y^{b}\right)\right)>0$. A similar calculation for $B(i i)$ yields (9) with the inequality reversed as a sufficient condition for local randomization when $\lambda_{b}>0$. Note that $w \psi^{\prime}(C)-\gamma^{\prime}(C)<0$ when $\lambda_{b}>0$ so that this is stricter than the necessary condition $B(i)$.

Conditions $(\mathrm{Ai})$ and $(\mathrm{Bi})$, which are mutually exclusive unless $\mathrm{I}_{\gamma}{ }^{\prime \prime}(\mathrm{L}) / \gamma^{\prime \prime}(\mathrm{L})=-2$, are sufficient conditions for no randomization to be desirable. Thus, randomization is desirable nowhere on the UPF if $L_{\gamma}{ }^{\prime \prime}(L) / \gamma^{\prime \prime}(L)=-2.14$ Furthermore, randomization cannot be desirable both with $\lambda_{a}>0$ and $\lambda_{b}>0$ unless $L_{r}{ }^{\prime \prime}(L) / \gamma^{\prime \prime}(L)+2$ changes sign along the UPF as labor supply changes. Since sufficient conditions for local randomization such as (7) and (8) are opposite in sign, randomization is desirable somewhere on the UPF, for many allowable $\gamma(\cdot)$ functions. 15 
III. Taxation in a Multiperiod Model

\section{A. Assumptions}

The model is an M period repetition of the one period world of section II ( $M$ may be finite or infinite). Two classes exist and each individual belongs to the same class across periods. The mmbers in each group remain constant over time. Preferences over income and consumption within each period satisfy (A1)-(A3) and are identical across periods. Lifetime utility is the present discounted value of the utility in the $M$ periods. Individuals in both classes have the same discount factor denoted $\rho$. Denoting $\hat{C}^{i}=\left(C_{1}^{i}, \ldots, C_{M}^{i}\right)$ and $\hat{Y}^{i}=$ $\left(Y_{1}^{i}, \ldots, Y_{M}^{i}\right)$ as the vectors of lifetime consumption and income for class $i$ and $\hat{V}^{i}\left(\hat{C}^{i}, \hat{Y}^{i}\right)$ as the lifetime utility function for class $i$, then

$$
\hat{V}^{i}\left(\hat{C}^{i}, \hat{Y}^{i}\right)=\sum_{t=1}^{M} \rho^{t-1} v^{i}\left(C_{t}^{i}, Y_{t}^{i}\right), \quad i=a, b
$$

It follows that if there is randomization, with the individuals offered lotteries over lifetime income-consumption vectors, then this lottery can be decomposed into separate lotteries in each period and expected lifetime utility equals the present discounted value of the expected utilities in the different periods.

Individuals are unable to save or to borrow across periods and thus face M separate budget constraints. This assumption is made to focus purely on the role of information transfer across periods in affecting taxation without complicating the analysis with possibility of wealth or interest taxation. In the first period, every individual faces the same tax function $\mathrm{T}^{1}\left(\mathrm{Y}_{1}\right)$ since the government has no basis upon which to distinguish individuals. Thereafter, the government can recall the incomes reported in previous periods and can condition the tax functions on previous periods' income. Thus, the tax 
function in period $t>1$, is written as $T^{t}\left(Y_{t} \mid Y_{1}, \ldots, Y_{t-1}\right)$. Taking the sequence of tax functions as given, each individual chooses lifetime consumption and income to solve the following maximization:

$$
\begin{aligned}
\left.\hat{M}^{i}, \hat{Y}^{i}\right) & \sum_{t=1}^{M} \rho^{t-1} V^{i}\left(C_{t}^{i}, Y_{t}^{i}\right) \\
\text { s.t. } & C_{I}^{i} \leqq Y_{1}^{i}-T^{1}\left(Y_{1}^{i}\right) \\
& C_{t}^{i} \leq Y_{t}^{i}-T^{t}\left(Y_{t}^{i} \mid Y_{1}^{i}, \ldots, Y_{t-1}^{i}\right), t=2, \ldots, M
\end{aligned}
$$

The solution gives lifetime consumption and income vectors as finctions of the vector of $\operatorname{tax}$ functions $\hat{C}^{i}\left(T^{1}, \ldots, T^{M}\right), \hat{Y}^{i}\left(T^{1}, \ldots, T^{M}\right)$.

Given the choices by individuals in each class and subject to budget balance requirements, the government chooses the set of tax functions to achieve its maximm. As in the one period model, the decision on the choice of tax functions can be transformed into choice of lifetime consumption income vectors for each class with $\left(\hat{C}^{a}, \hat{Y}^{a}\right)$ and $\left(\hat{C}^{b}, \hat{Y}^{b}\right)$ sustainable by a system of tax functions if and only if lifetime self-selection constraints are satisfied for each class. There is only one lifetime constraint for each class and not period by period self-selection constraints. In the first period, individuals will base their decisions whether or not to reveal their type through their choice of income on the entire lifetime consequences that follow. If individuals do reveal in the first period, the government knows thereafter who they are and can prevent them from acting as if they belonged to a different class. After revelation through their first period choices, the second and later period tax functions can incorporate a large penalty if any other bundle is chosen than the one the government desires them to choose. For example, a $\operatorname{tax}$ function of the form $T(Y)=Y, Y<\bar{Y}, T(Y)=Y+K-\bar{Y}, Y \geq \bar{Y}$, will induce the individual to produce income of $\bar{Y}$, raises revenue of $K$, for any $K \leq \bar{Y}$, and 
allows the individual to consume $\mathrm{C}=\mathrm{Y}-\mathrm{T}(\mathrm{Y})=\overline{\mathrm{Y}}-\mathrm{K}$. After the first period revelation, the individuals in later periods no longer find the bundle of the other group to be feasible. Hence, a self-selection constraint no longer constrains the governments' choices. Because the government has the ability to comit itself, and separation is desirable in a single period problem (Theorem II), separation will occur in every period.

Two separate budget balance requirements for the government are considered. One possibility is that the goverment has a single multiperiod budget constraint $\sum_{t=1}^{M} \delta^{t-1}\left[N_{a} T_{a}^{t}+N_{b} T_{b}^{t}\right] \geq 0$, where $T_{i}^{t}$ is the tax revenue raised from group $i$ in period $t$ and $\delta$ is the discount factor faced by the government. Alternatively, the government could be required to balance its budget separately in each period with $\mathrm{N}_{\mathrm{a}} \mathrm{T}_{\mathrm{a}}^{\mathrm{t}}+\mathrm{N}_{\mathrm{b}} \mathrm{T}_{\mathrm{b}}^{\mathrm{t}} \geq 0, t=1, \ldots, \mathrm{M}$. Clearly, the second is a tighter constraint on the government's choices. It reflects more closely the goal of considering pure information transfer between periods and is consistent with the no saving assumption for individuals. On the other hand, the single multiperiod constraint is justifiable if the government has access to possibilities not available to individuals such as a storage technology feasible only on a large scale or access to a world market closed to trade by individuals.

The goverment maximizes the present discounted value of a weighted sum of utilities in each period where the weights $\alpha$ and $(1-\alpha)$ are arbitrary and can vary to change the distribution between the groups but are constant over time. The government's discamt factor $\delta$ need not equal that of individuals. When they are equal $(\delta=\rho)$, the goverrment's maximization corresponds to finding the multiperiod Pareto frontier as a varies from 0 to 1 . When they differ $(\delta \neq \rho)$, the problem is no longer a Pareto problem since the goverment does not respect individuals' intertemporal preferences. While much literature analyzes why private and social discount rates could differ, these 
do not constitute the major reasons for allowing $\delta \neq \rho$ in this paper. The major focus is on the case of equal discount rates. Allowing them to differ gives rise to a case which serves as a useful benchmark for comparison when discussing the uses of information in the optimal tax structure. The use of information across periods when $\delta=\rho$ is much less systematic than when $\delta \neq \rho$.

With randomization not available to the government, we consider two maximization problems, (PIIIa) and (PIIIb), depending upon which budget constraint is used. For the single multiperiod constraint the problem is:

$$
\begin{aligned}
& \operatorname{Max} \sum_{t=1}^{M} \delta^{t-1}\left[\alpha N_{a} v^{a}\left(C_{t}^{a}, Y_{t}^{a}\right)+(1-\alpha) N_{b} V^{b}\left(C_{t}^{b}, Y_{t}^{b}\right)\right] \\
& \text { s.t. } \sum_{t=1}^{M} \rho^{t-1}\left[V^{i}\left(C_{t}^{i}, Y_{t}^{i}\right)-V^{i}\left(C_{t}^{j}, Y_{t}^{j}\right)\right] \geq 0, i=a, b, \quad j=i \\
& \sum_{t=1}^{M} \delta^{t-1}\left[N_{a}\left(C_{t}^{a}-Y_{t}^{a}\right)+N_{b}\left(C_{t}^{b}-Y_{t}^{b}\right)\right] \leq 0 \\
& 0 \leq Y_{t}^{i} \leq K^{i}, \quad i=a, b, \quad t=1, \ldots, M \\
& C_{t}^{i} \geq 0, \quad i=a, b, \quad t=1, \ldots, M
\end{aligned}
$$

For the separate constraints on each period, the problem is identical except that the constraint $\sum_{t=1}^{M} \delta^{t-1}\left[N_{a}\left(C_{t}^{a}-Y_{t}^{a}\right)+N_{b}\left(C_{t}^{b}-Y_{t}^{b}\right) \leq 0\right.$ is replaced by:

$$
N_{a}\left(C_{t}^{a}-Y_{t}^{a}\right)+N_{b}\left(C_{t}^{b}-Y_{t}^{b}\right) \leq 0, \quad t=1, \ldots, M
$$

The Lagrange multipliers on the self-selection constraints are still denoted by $\lambda_{a}$ and $\lambda_{b}$ although their values will differ between problems (PIIIa) and (PIIIb). The Lagrange multiplier on the single budget balance constraint in (PIIIa) is denoted by $\mu$ while $\mu_{t}, t=1, \ldots, M$ denote the multipliers on each period's budget balance constraint in (PIIIb).

Section B presents the case of $\delta=\rho$ and section $C$ the case of $\delta \neq \rho$. 
B. Optimal Taxation When $\delta=\rho$

Characterization theorems of the optimal solution in (PIIIa) similar to Theorems II and IV for (PI) and (PII) continue to hold. Let $C_{t}^{i}(\alpha)$ and $Y_{t}^{i}(\alpha)$, $t=a, b$, and $t=1, \ldots, M$, be the solutions to (PIIIa) as functions of $\alpha$. $v^{i t}(\alpha)$ denotes the optimal utility in period $t$ of individuals in class $i$ for (PIIIa). $v^{i o}, i=a, b$, again denotes one period utility with no taxes.

Theorem VII: The optimal solution to (PIIIa) satisfies the following properties:

(i) $\quad \operatorname{If} \sum_{t=1}^{M} \rho^{t-1} v^{i}(\alpha) \geq v^{i o} \sum_{t=1}^{M} \rho^{t-1}$ then $\sum_{t=1}^{M} \rho^{t-1} V^{i}\left(C_{t}^{j}(\alpha), Y_{t}^{j}(\alpha)\right)<\sum_{t=1}^{M} \rho^{t-1} v^{i t}(\alpha)$, $i=a, b$ and $j \neq i$.

(ii) If $\sum_{t=1}^{M} \rho^{t-1} v^{i t}(\alpha)=\sum_{t=1}^{M} \rho^{t-1} v^{i}\left(C_{t}^{j}(\alpha), Y_{t}^{j}(\alpha)\right)$ then $\sum_{t=1}^{M} \rho^{t-1} v^{j t}(\alpha)>$ $\sum_{t=1}^{M} \rho^{t-1} v^{j}\left(C_{t}^{i}(\alpha), Y_{t}^{i}(\alpha)\right), i=a, b$ and $j=i$.

(iii) $\mu>0$

(iv) If $\lambda_{i}=0$ then $C_{t}^{j}(\alpha)=C_{1}^{j}(\alpha), Y_{t}^{j}(\alpha)=Y_{1}^{j}(\alpha)$ and $M S^{j}\left(C_{t}^{j}(\alpha), Y_{t}^{j}(\alpha)\right)=1$, $i=a, b, j=i, t=1, \ldots, M$

(v) For $i=a, b$ and $j \neq i$, if $\lambda_{i}>0$ then at each $t=1, \ldots, M$ either:

$$
\begin{aligned}
& 1<\mathbb{R R}^{j}\left(C_{t}^{j}(\alpha), Y_{t}^{j}(\alpha)\right)<\operatorname{MRS}^{i}\left(C_{t}^{j}(\alpha), Y_{t}^{j}(\alpha)\right) \\
& \operatorname{MRS}^{i}\left(C_{t}^{j}(\alpha), Y_{t}^{j}(\alpha)\right)<\mathbb{R S S}^{j}\left(C_{t}^{j}(\alpha), Y_{t}^{j}(\alpha)\right)<1 \\
& \operatorname{MRS}^{i}\left(C_{t}^{j}(\alpha), Y_{t}^{j}(\alpha)\right)=\mathbb{R S}^{j}\left(C_{t}^{j}(\alpha), Y_{t}^{j}(\alpha)\right)=1
\end{aligned}
$$

Proof: See the Appendix. 
From part ( $v$ ) it follows that even if information is utilized, if distortions exist in the first period then they persist in future periods. Thus, information learned camnot be fully used to move to a first best result after the first period. The government must commit itself to use information only to a limited extent.

Theorem VII does not show that the government will use any information gained in the first period to affect later period taxes. In fact, a simple repetition of the one period nonrandam solution to (PI) satisfies all the first order conditions in (PIIIa). However, despite the apparent symmetry of the first order conditions, multiple asymmetric solutions may arise in the form of nonstationarity of the optimal consumption-income vectors. Such nonstationary solutions arise from the same nonconvexity of the self-selection constraints that gives rise to random solutions in the one period problem. In fact, the following theorems show that there is an exact malogy between existence of a nondegenerate solution to (PII) and a nonstationary solution to (PIIIa). Let $\hat{V}^{i}(\alpha)=\sum_{t=1}^{M} \rho^{t-1} v^{i}\left(C_{t}^{i}(\alpha), Y_{t}^{i}(\alpha)\right) / \sum_{t=1}^{M} \rho^{t-1}, i=a, b$, be the average utility achieved by each group over its lifetime. Let the normalized utility possibility frontier be the utility possibility frontier in average utilities.

Theorem VIII: Assume $\rho=\delta \geq 2 / 3$ and $M=\infty$. Then for every $\alpha$, there exists a solution to (PIIIa). This solution involves nonstationarity iff $k(i)>1$, $i=a$ or $b$, in (PII). In addition, the normalized Pareto frontier arising in (PIIIa) is identical to that in (PII). Proof: See the Appendix.

Given an infinite horizon and a large enough discount factor, any one period random solution can be exactly duplicated by a nonstationary solution. The circumstances in Theorem V and VI under which randomization will arise are thus sufficient for nonstationary solutions. Even if $M$ is finite or $\delta$ is small, nonstationarity can arise. 
Theorem IX: If $\delta=\rho$ and if $M$ is finite or $\delta<2 / 3$, then the normalized Pareto frontier for (PIIIa) may be interior to that for (PII). For any $\alpha$, a solution will involve nonstationarity only if $k(i)>i, i=a$ or $b$ in (PII). For $\delta \geq 2 / 3$, there exists a sufficiently large finite $M$ such that nonstationarity in a solution to (PIIIa) arises iff $k(i)>1, i=a$ or $b$ in (PII). Proof: See the Appendix.

In many cases, the result for finite $M$ or $\delta<2 / 3$ may be stronger. As shown in Theorem VI, when some local randomization improves on the nonrandom solution, then there exists a randomization with any probabilities in the probability simplex which improves on the nonrandon solution. In this case, even though the optimal solution to (PII) camot be duplicated, a nonstationary solution to (PIIIa) exists iff a local nonrandom solution exists in (PII).

Problem (PIIIb) is the case of pure information transfer across periods since neither the government nor individuals can borrow or save. It is not possible to duplicate the one period random solution by nonstationarity unless randomization was over bundles with $C^{i h}-Y^{i h}=\left(N_{j} / N_{i}\right)\left(C^{j}-Y^{j}\right), h=1,2,3$. This is not always true as shown by the example in Theorem VI where only income is random. Nevertheless, nonstationarity may still arise in (PIITb) as long as randomization arises in (PIITb). The Appendix contains a characterization of the solution to (PIIIb) as Theorem Al.

The only significant difference between the results for (PIIIb) and those for (PIIIa) is that it camot be shown that the same bundle is given in every period to group $j$ if group $i$ 's self-selection constraint is not binding. However, any nonstationarity for group $j$ is over bundles with no distortion.

Theorem X: If $\rho=\delta$, nonstationarity is possible in the solution to (PIIIb) and arises only if $k(i)>1, i=a$ or $b$, in (PII). The normalized Pareto frontier found in (PIIIb) is generally interior to that in (PIIIa) whenever the solution to (PIIIa) involves nonstationarity. Proof: See the Appendix. 
If randomess within periods is permitted as well as nonstationarity of the tax schedules, clearly, the government can do as well as in the solution to (PII). This is true for finite $M$ and any discount rate. Only if random solutions are used for (PII) will either random or nonstationary solutions be used in the multi-period problem, regardless of whether the budget constraint is a single one or a period-by-period one. Allowing both types of variation leads to multiple optimal solutions which combine randomization and nonstationarity in different ways.

\section{Optimal Taxation when $\delta \neq \rho$}

When the government and individuals have different discount rates, systematic nonstationarity arises in the optimal solution. To contrast with the nonsystematic nonstationarity when $\delta=\rho$, only results for (PIIIa) are given. Similar results hold if period-by-period budget balance is required or if additional randomization is allowed. Note that similar results arise if the two classes had different private discount rates instead of identical private rates different from the government's.

The first order conditions in (PIIIa) are:

$$
\begin{aligned}
& {\left[\delta^{t-1} \alpha N_{a}+\lambda_{a} \rho^{t-1}\right]\left(\partial V^{a} / \partial C_{t}^{a}\right)-\lambda_{b} \rho^{t-1}\left(\partial V^{b} / \partial C_{t}^{a}\right)-\mu \delta^{t-1} N_{a}=0,} \\
& t=1, \ldots, M \\
& {\left[\delta^{t-1} \alpha N_{a}+\lambda_{a} \rho^{t-1}\right]\left(\partial V^{a} / \partial Y_{t}^{a}\right)-\lambda_{b} \rho^{t-1}\left(\partial V^{b} / \partial Y_{t}^{a}\right)-\mu \delta^{t-1} N_{a}=0,} \\
& t=1, \ldots, M \\
& {\left[\delta^{t-1}(1-\alpha) N_{b}+\lambda_{b} \rho^{t-1}\right]\left(\partial V^{b} / \partial C_{t}^{b}\right)-\lambda_{a} \rho^{t-1}\left(\partial V^{a} / \partial C_{t}^{b}\right)-\mu \delta^{t-1} N_{b}=0,} \\
& t=1, \ldots, M \\
& {\left[\delta^{t-1}(1-\alpha) N_{b}+\lambda_{b} \rho^{t-1}\right]\left(\partial V^{b} / \partial Y_{t}^{b}\right)-\lambda_{a} \rho^{t-1}\left(\partial V^{a} / \partial Y_{t}^{b}\right)+\mu \delta^{t-1} N_{b}=0,} \\
& t=1, \ldots, M
\end{aligned}
$$

When $\delta>\rho$, it follows from these conditions that as $t$ increases, the economy approaches the single period first best UPF for any values of $\lambda_{a}$ and 
$\lambda_{b}$. This, of course, does not mean that the normalized UPF based on average utilities is the first best.

Theorem XI: Consider (PIIIa) when $\delta>\rho$ and $M=\infty$. Assume that the utility functions satisfy the conditions that $\lim \left(\partial V^{a} / \partial C\right) /\left(\partial V^{b} / \partial C\right)$ and $\lim _{b}\left(\partial V^{a} / \partial Y\right) /\left(\partial V^{b} / \partial Y\right)$ are finite. Then, when $\lambda_{b}=0$ and $\lambda_{a}>0$, $\lim _{t \rightarrow \infty} \operatorname{MRS}^{b}\left(C_{t}^{b}, Y_{t}^{b}\right)=1$. Since $\operatorname{MRS}^{a}\left(C_{t}^{a}, Y_{t}^{a}\right)=1$, for all $t$, as $t$ grows, the optimm approaches the period-by-period Pareto frontier.

Proof: Given $\lambda_{b}=0$, equations (1la) and (1lb) yield $\operatorname{MRS}^{a}\left(C_{t}^{a}, Y_{t}^{a}\right)=1$, for all t. Divide equation (11c) $b z \delta^{t-1}\left(\partial V^{b} / \partial C_{t}^{b}\right)$ and (11d) by $\delta^{t-1}\left(\partial V^{b} / \partial Y_{t}^{b}\right)$.

$$
\begin{aligned}
& (1-a) N_{b}-\lambda_{a}(\rho / \delta)^{t-1}\left[\left(\partial V^{a} / \partial C_{t}^{b}\right) /\left(\partial V^{b} / \partial C_{t}^{b}\right)\right]-\mu N_{b} /\left(\partial V^{b} / \partial c_{t}^{b}\right)=0, \\
& t=1, \ldots, M \\
& (1-\alpha) N_{b}-\lambda_{a}(\rho / \delta)^{t-1}\left[\left(\partial V^{a} / \partial Y_{t}^{b}\right) /\left(\partial V^{b} / \partial Y_{t}^{b}\right)\right]-\mu N_{b} /\left(\partial V^{b} / \partial Y_{t}^{b}\right)=0, \\
& t=1, \ldots, M
\end{aligned}
$$

Since $\partial V^{i} / \partial C$ is finite for $C>0$ and $\lim \left(\partial V^{a} / \partial C\right) /\left(\partial V^{b} / \partial C\right)$ is finite, $\lim \sup (\rho / \delta)^{t-1}\left[\left(\partial V^{a} / \partial C_{t}^{b}\right) /\left(\partial V^{a} / \partial C_{t}^{b}\right)\right] \stackrel{C+0}{=} 0$. Hence, should $\lim \sup \left(\partial V^{b} / \partial C\right)=\infty$ then after some $\hat{t}$, the left hand side of $(12 a)$ would be strictly positive violating the first order condition. Thus, no $\mathrm{C}_{t}^{\mathrm{b}}$ sequence goes to zero, guaranteeing that $\lim _{t \rightarrow \infty} \inf C_{t}^{b}>0$. Similarly, from $(12 b), \lim _{t \rightarrow \infty} \sup Y_{t}^{b}<K^{b}$. Therefore, $\lim \sup (\rho / \delta)^{t-1}\left(\partial V^{b} / \partial c_{t}^{b}\right)=\lim _{t \rightarrow \infty} \sup (\rho / \delta)^{t-1}\left(\partial V^{b} / \partial Y_{t}^{b}\right)=0$. Given this, divide (11c) and (1ld) by $\delta^{t-1}$ and solve for $\operatorname{MRS}^{b}\left(C_{t}^{b}, Y_{t}^{b}\right)=$ $-\left(\partial V^{b} / \partial Y_{t}^{b}\right) /\left(\partial V^{b} / \partial C_{t}^{b}\right)$.

$$
\operatorname{MRS}^{b}\left(C_{t}^{b}, Y_{t}^{b}\right)=\frac{\mu N_{b}-\lambda_{a}(\rho / \delta)^{t-1}\left(\partial V^{a} / \partial Y_{t}^{b}\right)}{\mu N_{b}+\lambda_{a}(\rho / \delta)^{t-1}\left(\partial V^{a} / \partial C_{t}^{b}\right)}
$$

then $\lim _{t \rightarrow \infty} M^{b} S^{b}\left(C_{t}^{b}, Y_{t}^{b}\right)=1$ 
Note that the conditions on utility given in this theorem can be satisfied by the utility functions in Theorem VI with $w_{a}>w_{b}$. Given the separability, $\left(\partial \mathrm{V}^{\mathrm{a}} / \partial \mathrm{C}\right) /\left(\partial \mathrm{V}^{\mathrm{b}} / \partial \mathrm{C}\right)=\mathrm{I}$ at all $\mathrm{C}$. The maximm income earned by the able exceeds that earned by the unable $K^{a}>K^{b}$. Hence, even if $\partial \gamma / \partial L$ goes into infinity as $\mathrm{L}$ approaches it maximm value at $\mathrm{K}^{i} / \mathrm{w}^{i}$, since $\mathrm{K}^{\mathrm{b}} / \mathrm{w}_{\mathrm{a}}<\mathrm{K}^{\mathrm{a}} / \mathrm{w}^{\mathrm{a}}$, then $\partial \gamma\left(K^{b} / w_{a}\right) / \partial Y$ and $\lim _{y+K^{b}}\left(\partial V^{a} / \partial Y\right) /\left(\partial V^{b} / \partial Y\right)$ are finite.

Different discount rates cause the government and individuals of type A to have difference preferences. Therefore, trade between them is possible. The government places a higher value on the future than do individuals. Hence, the government can offer type A individuais higher current utility and lower future utility while doing the reverse for type $B$ as compared to the solution when $\delta=\rho$. Self-selection will contimue to be satisfied given the value of $\rho$ but social welfare rises. To see this, note that from equation (11a) and (1lb), $\partial V^{a} / \partial C_{t}^{a}=-\partial V^{a} / \partial Y_{t}^{a}={ }_{\mu} N_{b} /\left[\alpha N_{a}+\lambda_{a}(\rho / \delta)^{t-1}\right]$. Hence, marginal utility of consumption rises over time indicating that consumption declines. As $t$ goes to infinity, $\alpha \partial \mathrm{V}^{\mathrm{a}} / \partial \mathrm{C}_{t}^{\mathrm{a}}$ goes to $\mu$. For group $\mathrm{B}$ consumption, $(1-\alpha)\left(\partial V^{b} / \partial C_{t}^{b}\right)=\mu+\left(\lambda_{a} / N_{b}\right)(\rho / \delta)^{t-1}\left(\partial V^{a} / \partial C_{t}^{b}\right)$, which since lim inf $C_{t}^{b}>0$, must at least eventually decline with $C_{t}^{b}$ rising. As $t$ goes to infinity, $(1-\alpha)\left(\partial V^{b} / \partial C_{t}^{b}\right)$ goes to $\mu$. Thus, in the limit, the solution is not only Pareto optimal but it is first best in the sense of being the same as the solution to the one period problem without self-selection constraints.

If $\delta<\rho$, the trade is still possible but tends to go in the opposite direction. As $t$ goes to infinity, $C_{t}^{a}$ goes to infinity and $Y_{t}^{a}$ goes to zero along a path with $\operatorname{MRS}^{a}\left(C_{t}^{a}, y_{t}^{a}\right)=1$, at all t. Thus, A's utility rises over time. ${ }^{16}$ From (11c), it follows that $c_{t}^{b}$ must also go to infinity as $t$ rises. However, $\mathrm{Y}_{t}^{\mathrm{b}}$ going either to 0 or to $\mathrm{K}^{\mathrm{b}}$ could be consistent with the first order condition (11d). Whatever the specific solution, in this case as when $\delta$ $>\rho$, the paths of commodities and utilities move systematically over time and do not vary solely to mimic randomization. 
IV. Conclusions

These results indicate that when the goverment respects individual discount rates, only in a weak sense does the optimal tax system incorporate any information about individuals learned from their responses over time. First, if the government is able to randomize in each period, then no benefit is gained by keeping track of what individuals have earned in past periods. A lottery can be offered in each period, independent of other periods, satisfying self-selection constraints and yielding the best possible outcome. Second, if the govermment camnot randomize directly, then it can duplicate randomization by intertemporal nonstationarity. Juch nonstationarity requires that the government keep track of individuals' past behavior since, after the first period, self-selection constraints need not be satisfied. Third, even when the government must keep track of behavior and uses this in future periods, the information is not used systematically to yield continued increases in the government objective function over time. Instead, changes in the weighted sum of utilities across periods occurs only as the goverrment tries to mimic a one period random optimum. If tax schedules must vary over time in a particular mamer, it is not because of the need to learn individuals' abilities, but because utility in each period must be ordered correctly to be consistent with lifetime utility constraints.

By contrast, when the government discounts at a different rate than individuals, then there is systematic change in the bundles given to individuals. In the limit, the distortions may be eliminated. This arises because the different intertemporal preferences of the goverrment and individuals leaves room for "trade" between them. Over time the differences between the utilities of the groups grows larger.

The results in this paper show that nonstationarity over time and randomization within each period can substitute for each other in the optimal 
intertemporal income tax. It is not clear which approach is preferable since each has some advantages.

First, they are not perfect substitutes. Even if the government has a single intertemporal budget balance constraint, nonstationarity is guaranteed to do as well as randamization only with an infinite horizon and a sufficiently large discount factor. If the goverrment has a separate budget constraint in each period, the optimal randomization cannot be completely duplicated by intertemporal variability, so that randomization along with nonstationarity would be needed to reach this Pareto frontier.

Second, political and administrative difficulties could prevent implementation of either method. On one hand, the government may be reluctant to incorporate randomization explicitly in the tax code. This is especially true since the optimal randomization requires individuals to declare their type and then receive at random a tax schectule before choosing their labor supplies. The optimal randomization can generally not be implemented by random collection or enforcement after labor supply decisions. On the other hand, intertemporal nonstationarity requires keeping track of past labor supply decisions to determine individuals' current tax payments. However, this is simplified since the government needs only to recall each individual's type as revealed by past decisions instead of relearning this each period as is required by randomization.

Third, both ethically and to increase acceptance of the tax system by society, it is desirable that the system be perceived as fair. A standard notion of faimess is horizontal equity, that individuals in the same circumstances be treated the same. Randomization satisfies horizontal equity ex ante but not ex post. Before the random selection, all individuals of the same type face the same lottery. After receiving a randam draw of tax functions, individuals of the same type will be induced to choose bundles 
which need not yield the same utility. Note, however, that suboptimal randomization in which ex post horizontal equity is imposed may often still be better than no randomization as the proof of Theorem $\mathrm{V}$ demonstrates. Intertemporal nonstationarity achieves horizontal equity both ex ante and ex post in each period. Individuals of the same type are induced to choose the same bundles as each other in every period even though the choice varies over time.

Fourth, both procedures induce asymmetries in the bundles chosen by individuals of a type either within a period in an expected sense under randomization or over time under nonstationarity. With strictly concave utility functions, individuals desire to reduce these asymetries. Under randomization, individuals might gain by purchasing insurance counteracting the randamess in the tax system. If such policies were forbidden, then similar effects could be achieved by trades with other individuals of the same type. For the same reason, under nonstationarity, individuals desire to smooth consumption and leisure over time by saving or borrowing. Saving or insurance serves to counteract the weakening of self-selection constraints which motivated asymmetry of bundles in the first place. The ability to save or buy insurance will be a factor in the decision to reveal one's type truthfully. The choice between nonstationarity or randomess may depend upon whether it is easier to prevent saving or insurance. If these are desirable for other reasons or camnot be prevented, then the simple repetition of the solution to (PI) may be the best feasible solution. However, the opposite problem arises if only symmetric solutions are allowed when individuals have nonconvex opportunity sets. Individuals may desire randomization of consumption about their bundles to convexify budget sets. Thus, gambling might have to be inhibited by the government. Any nonconvex tax structure must account for additional markets whose use might be encouraged by the tax structure. 


\section{Footnotes}

1. Guesnerie and Seade [1982] derived some results without global single crossing, but they assumed that MRS's were not equal at the optimal bundles. We only assume that tangencies do not lie on the no-tax budget line and show that the MRS's are not equal at an optimm.

2. This requires an additional assumption on $U(C, L)$. Note that $M_{R} S^{i}(C, Y)=$ $-\left[U_{L}\left(C, L^{i}\right) / w^{i} U_{C}\left(C, L^{i}\right)\right]$. If $w^{a}>w^{b}$ then $L^{a}<L^{b}$. The result holds if the direct effect of the higher wage is not countered by the effects of a lower $\mathrm{L}$ on the MRS. Differentiating $-\left[\mathrm{U}_{\mathrm{L}}(\mathrm{C}, \mathrm{Y} / \mathrm{w}) / \mathrm{wU}_{\mathrm{C}}(\mathrm{C}, \mathrm{Y} / \mathrm{w})\right]$ with respect to $w$ yields $d M R S(C, Y) / d w=\left(U_{L} / w_{C}\right)-\left(L / w^{2}\right) d\left(-U_{L} / U_{C}\right) / d L$. A sufficient condition for $\operatorname{dMRS}(\mathrm{C}, \mathrm{Y}) / \mathrm{dw}<0$ is $\mathrm{d}\left(-\mathrm{U}_{\mathrm{L}} / \mathrm{U}_{\mathrm{C}}\right) / \mathrm{dL} \geq 0$ which holds if $\mathrm{C}$ is not inferior. See Sadka [1976].

3. The schecule $T(Y)$ need not be differentiable. In fact, it will generally be nondifferentiable at the incomes chosen by the two groups.

4. A lower ability class might be unable to produce the incame of a higher ability class. Such bundles can be assigned arbitrarily low utilities.

5. The results are essentially unchanged if taxes had to raise net revenue as well as redistributing across groups.

6. Other tax functions could yield the same result as long as the slope of the individual budget constraint is greater than both MRS's, for Y less than $\mathrm{Y}^{\mathrm{i}}$, and is smaller than both $M \mathbb{R S}^{\prime} \mathrm{s}$, for $\mathrm{Y}$ greater than $\mathrm{Y}^{\mathrm{i}}$.

7. A self-selection constraint may hold with equality so that one of the groups may be indifferent between the two bundles offered. The solution requires that all individuals in the group choose the bundle aimed at that group. This can be achieved by assuming that the government can assign indifferent individuals to whichever group it desires. Given that the govertment does not know to which group a particular individual belongs, this is not a reasonable assumption. An alternative view is that the solution to (PI) is really an $\varepsilon$-equilibrium. Although it camot itself be achieved, a bundle arbitrarily close to that solution can be found 
which satisfies resource balance and which has the self-selection constraint hold with strict inequality. If the self-selection constraints must hold with strict inequality, then there may exist no solution to the maximization problem.

8. This is true provided the group whose self-selection constraint does not bind does not have its weight equal 0 . However, if $\alpha=0$ then B's self-selection constraint camnot bind since resources are being transferred to B. Similarly, if $\alpha=1$, then A's self-selection constraint camnot bind. In addition, there is an implicit assumption that the maximized value as a function of $\gamma$ does not have an inflection point at $r=0$. Constraint qualification rules out such a possibility.

9. If ex ante randomization is not possible, then ex post randomization might still be desirable.

10. Again, if post revelation randomess is not possible, the prerevelation randamness may be desirable since it weakens the budget constraint of the govermment. Such prerevelation randomess can be desirable if there are nonconvexities in the utility possibility frontier (see Stiglitz [1982a]).

11. In (PI), the bounds on $\mathrm{Y}^{i}$ along with resource balance automatically bound $\mathrm{C}^{i}$. Here, bounds on $\mathrm{C}^{\mathrm{i} h}$ do not follow from the expected resource constraint since that constraint bounds the products $\pi_{i h} C^{\text {ih }}$ only. As same $\pi_{\text {ih }}$ goes to zero, the corresponding $C^{\text {ih }}$ could be made arbitrarily large. The $\mathrm{M}^{i}$ could be chosen sufficiently large to bound the feasible set without affecting the solution.

12. To guarantee ex post resource balance for all realizations of all randam mechanisms, a stronger constraint must be imposed:

$$
\mathrm{N}_{\mathrm{a}} \underset{\mathrm{h}}{\operatorname{Max}}\left[\mathrm{C}^{\mathrm{ah}}-\mathrm{Y}^{\mathrm{ah}}\right]+\mathrm{N}_{\mathrm{b}} \underset{\mathrm{h}}{\operatorname{Max}}\left[\mathrm{C}^{\mathrm{bh}}-\mathrm{Y}^{\mathrm{bh}}\right] \leqq 0
$$

where the max's are over those bundles with nonzero probability. Condition (F1) says that, even if all individuals receive the bundle with the largest difference between $C$ and $Y$, resource balance still holds. 
For some types of randomization, (F1) may be required. For example, assume, in the lotteries, that one tax schedule (that is, one bundle) is chosen for every individual of a type. The objective function and self-selection constraints are unaffected by the mamer in which randomization occurs. If (F1) is violated, then there is clearly some positive probability of assigning more consumption than is available. On the other hand, for many mechanisms, (F1) is far too restrictive. It rules out balancing large consumption to some people from a favorable draw for them against low consumption to others of the same type. This can be achieved without violating the feasibility constraint ex post as discussed in the text.

13. This result holds not just because little redistribution is desired with similar abilities so that neither self-selection constraint binds. If $\alpha=0$ in (PI) and the A's are more able, redistribution is carried out so that A's self-selection constraint binds. Randomization will not improve on this solution.

14. If $\gamma=K_{1} \operatorname{lnL}+K_{2} L$, where $K_{1}<0$ and $K_{2}>0$, then $L_{\gamma}{ }^{\prime \prime} / \gamma^{\prime \prime \prime}=-2$ so that randomization will never occur. $\left(\gamma^{\prime}>0\right.$ can be assumed by the function at small values of L.) If there is quadratic disutility of labor with $\gamma$ $=\mathrm{KL}^{2}$, then $(\mathrm{A} i$ ) is satisfied so that randomization does not occur when $\lambda_{a}>0$. Substituting into (Bii) shows that local randomization camot occur when $\lambda_{b}>0$. Whether nonlocal randomization can occur is unclear.

15. Stiglitz [1982a] derived the conditions in Theorem VI and Corollary III as sufficient for local randomization over two bundles arising with equal probability. The results here are stronger: these conditions are both necessary and sufficient for any local randomization to exist which improves on the nomrandom solution. The same condition applies with any arbitrary probabilities over three bundles. Due to an error in calculation, Stiglitz [1982a] asserts a result opposite that of Corollary II.

16. Transversatility conditions must be checked to guarantee that this is a valid solution. 


\section{References}

Arnott, R.J. and J.E. Stiglitz, "Randomization with Asymmetric Information: A Simplified Exposition," mimeo, 1985.

Fellingham, J.C., Y.K. Kwon and D.P. Newman, "Ex Ante Randomization in Agency Models," Rand Joumal of Economics 15: 290-301 (1984).

Guesnerie, R. and J. Seade, "Nonlinear Pricing in a "Finite Economy," Journal of Public Economics 17: 157-179 (1982).

Maskin, E. and J. Riley, "Optimal Auctions with Risk-Averse Buyers," Econometrica 52: 1473-1518 (1984).

, "Income v. Leisure Taxes," Discussion paper no. 174, UCLA Department of Economics, August 1980.

Mirrlees, J.A., "An Exploration in the Theory of Optimm Income Taxation," Review of Econamic Studies 38: 175-208 (1971).

Sadka, E., "On Income Distribution, Incentive Effects and Optimal Incame Taxation," Review of Economic Studies 43: 261-268, (1976).

Stiglitz, J.E., "Self-Selection and Pareto Efficient Taxation," Joumal of Public Economics 17: 213-240 (1982a).

, 'Utilitarianism and Horizontal Equity: The Case for Random Taxation," Joumal of Public Economics 18: 1-33 (1982b).

Weiss, L.W., "The Desirability of Cheating Incentives and Randamess in the Optimal Income Tax," Journal of Political Economy 89: 1343-1352 (1976). 


\section{APPENDIX}

\section{PROOFS OF THEOREMS}

PROOF OF THEOREM IV: (i) Let $\mathrm{c}^{i}(\alpha) \equiv \sum_{h=1}^{k(i)} \pi_{i h}(\alpha) C^{i h}(\alpha)$ and $\bar{Y}^{i}(\alpha) \equiv \sum_{h=1}^{k(i)} \pi_{i h}(\alpha) Y^{i h}(\alpha), i=a, b$. Then since $V^{i}\left(C^{i}, Y^{i}\right)$ is strictly concave, $\mathrm{V}^{i}\left(\widetilde{C}^{i}(\alpha), \overline{\mathrm{Y}}^{i}(\alpha)\right) \geq \mathrm{EV}^{i}(\alpha)$, with strict inequality if the $i$ lottery is nondegenerate. $\operatorname{If} \sum_{h=1}^{k(j)} \pi_{j h}(\alpha) v^{i}\left(C^{j h}(\alpha), Y^{j h}(\alpha)\right)=E V^{i}(\alpha)$ then $V^{i}\left(C^{j}(\alpha)\right.$, $\left.\overline{\mathrm{Y}}^{j}(\alpha)\right) \geq \mathrm{EV}^{\mathrm{i}}(\alpha)$, with strict inequality if the $\mathrm{j}$ lottery is nondegenerate, also follows from the strict concavity. By assumption, $\operatorname{EV}^{i}(\alpha) \geq V^{i 0}$ so that $V^{i}\left(\bar{C}^{i}(\alpha), \bar{Y}^{i}(\alpha)\right) \geq v^{i o}$ and $V^{i}\left(\bar{C}^{j}(\alpha), \bar{Y}^{j}(\alpha)\right) \geq v^{i o}$ must hold. Since the indifference curve through $\mathrm{V}^{\mathrm{io}}$ is tangent to the line $\mathrm{C}=\mathrm{Y}, \overline{\mathrm{C}}^{i}(\alpha)>\overline{\mathrm{Y}}^{i}(\alpha)$ and $\bar{C}^{j}(\alpha)>\bar{Y}^{j}(\alpha)$ must hold. Hence, $N_{i}\left(\bar{C}^{i}(\alpha)-\bar{Y}^{i}(\alpha)\right)+N_{j}\left(\bar{C}^{j}(\alpha)-\bar{Y}^{j}(\alpha)\right)>0$ must hold. But $N_{i} \sum_{h=1}^{k(i)} \pi_{i h}(\alpha)\left(C^{i h}(\alpha)-Y^{i h}(\alpha)\right)+N_{j} \sum_{h=1}^{k(j)} \pi_{j h}(\alpha)\left(C^{j h}(\alpha)-Y^{j h}(\alpha)\right)$ $=N_{i}\left(\bar{C}^{i}(\alpha)-\bar{Y}^{i}(\alpha)\right)+N_{j}\left(\bar{C}^{j}(\alpha), \bar{Y}^{j}(\alpha)\right)$ so resource balance is violated unless the self-selection constraint for $i$ holds with strict inequality.

(ii) Since even with randomization the point $\left(v^{a o}, v^{b o}\right)$ must lie on the constrained utility possibility frontier, the proof follows as in that for Theorem II.

(iii) Given (ii), this result follows exactly as the corresponding result in Theorem II.

(iv) Consider the first order conditions with respect to each $c^{j h}$ and $\mathrm{Y}^{\mathrm{jh}}$ in maximization problem (PII). In each condition, $\pi^{\text {jh }}$ multiplies every term so it drops out leaving conditions identical in form to those in (PI). Since $\lambda_{i}=0$, it is immediate that at each $h, \operatorname{MRS}^{j}\left(C^{j h}, \mathrm{Y}^{j h}\right)=1$.

To see that $k(j)>1$ is not needed at an optimm, consider the case where the self-selection constraint for group $i$ holds with strict inequality (that 
is, $\left.\sum_{h=1}^{k(i)} \pi_{i h} V^{i}\left(C^{i h}, Y^{i h}\right)>\sum \pi_{j h} V^{i}\left(C^{j h}, Y^{j h}\right)\right)$. Having $k(j)>1$ in a nondegenerate lottery so there exist $h$ and $k$ with $\pi_{j h}$ and $\pi_{j k}$ positive and $\left.\left(C^{j h}, Y^{j h}\right)=\left(C^{j k}, Y^{j k}\right)\right)$ carmot be optimal. With the probabilities fixed, consider a change in the $\left(\mathrm{C}^{\mathrm{jh}}, \mathrm{Y}^{\mathrm{jh}}\right)$ which moves each closer to the mean bundle without changing the mean. Such a shift will continue to satisfy both the bounds on the $\mathrm{C}^{\mathrm{jh}}$ and $\mathrm{Y}^{\mathrm{jh}}$ and the resource balance constraint. The probabilities do not change, satisfying the constraints that they sum to 1 . From concavity, $\sum_{h=1}^{k(j)} \pi_{j h} \mathrm{v}^{i}\left(C^{j h}, \mathrm{Y}^{j \mathrm{~h}}\right)$ will rise but since the self-selection constraint for $i$ holds with strict inequality, if the shift is not too large, this constraint will still hold. Since $\sum_{h=1}^{k(j)} \pi_{j h} v^{j}\left(c^{j h}, y^{j h}\right)$ rises, the self-selection constraint for group $\mathrm{j}$ must still hold. Thus, the bundles after the shift yield a feasible lottery. Since $\sum_{h=1}^{k(j)} \pi_{j h} V^{j}\left(C^{j h}, Y^{j h}\right)$ rises, the objective function rises showing that the prior bundle was not optimal.

(v) The first order conditions with respect to $C^{j h}$ and $Y^{j h}$ are the same as those for $\mathrm{C}^{j}$ and $\mathrm{Y}^{j}$ in (PI) since the $\pi_{j h}$ cancel from the conditions. Hence, the relations here can be shown exactly as in the proof of the Theorem II. Unlike in that theorem, equal MRS's equal to unity can not be ruled out. To see that $k(j)>3$ is not required, consider the optimal lotteries. Fix the quantities $\left(C^{i h}, \mathrm{Y}^{\mathrm{ih}}\right.$ ), $i=a, b$, and $\mathrm{h}=1, \ldots, \mathrm{k}(\mathrm{i})$. Consider (PII) as a linear programming problem in the $\pi_{i h}$. From part (iv), one of the lotteries is degenerate with $\pi_{j i}=1$. From part (ii), at most one self-selection constraint can bind. Thus, of the five original constraints, at most three (a self-selection constraint, the resource balance constraint, and the constraint that the probabilities in the nondegenerate lottery sum to 1) are binding. A solution exists with the muber of nonzero variables no greater than the muber of binding constraints. Q.E.D. 
PROOF OF THEOREM V: The proof requires the following lemma.

Lemma I: Consider any utility function $U(X)$, any bundles $X^{1}, X^{2}$, and $X^{3}$ with $U\left(X^{1}\right)>U\left(X^{2}\right)$ and $U\left(X^{3}\right)>U\left(X^{2}\right)$, and any $\pi, 0<\pi<1$. There exists some concave increasing transformation $V(X)=F(U(X))$ such that $\pi V\left(X^{I}\right)+(1$ $\pi) V\left(X^{2}\right)<V\left(X^{3}\right)$.

Proof: It is sufficient to provide an example of a transformation under which the result holds. Let $U^{2} \equiv U\left(X^{2}\right)$ consider $F_{n}(U)=\left(U-U^{2}\right)^{1 / n}$. Then $V_{n}\left(x^{2}\right)=\left(U\left(x^{2}\right)-U^{2}\right)^{1 / n}=0$ for all $n$. The result then reduces to there existing an $n^{*}$ with $\pi_{n^{*}}\left(x^{1}\right)<V_{n^{*}}\left(X^{3}\right)$. This in turii follows if there exists am $n^{*}$ for which $V_{n^{*}}\left(x^{3}\right) / V_{n *}\left(X^{1}\right)=\left[\left(U\left(x^{3}\right)-U^{2}\right) /\left(U\left(X^{1}\right)-U^{2}\right)\right]^{1 / n}>\pi$. Since $\lim _{n \rightarrow \infty}\left[\left(U\left(X^{3}\right)-U^{2}\right) /\left(U\left(X^{1}\right)-U^{2}\right)\right]^{1 / n}=1$ and since $\pi<1$, the existence of the required $n *$ follows.

Proof of Theorem: Given $\alpha$, let $\left(C^{i}, Y^{i}\right)$ and $\left(C^{j}, Y^{j}\right)$ be the solutions to (PI). Since $\lambda_{i}>0$ and $\operatorname{MRS}^{j}\left(C^{j}(\alpha), Y^{j}(\alpha)\right) \neq I$ from Theorem II $(v)$, there must exist two bundles $\left(C^{j 1}, Y^{j 1}\right)$ and $\left(C^{j 2}, Y^{j 2}\right)$ with $V^{j}\left(C^{j 1}, Y^{j 1}\right)=V^{j}\left(C^{j 2}, Y^{j 2}\right)=$ $\mathrm{V}^{\mathrm{j}}\left(\mathrm{C}^{\mathrm{j}}(\alpha), \mathrm{Y}^{\mathrm{j}}(\alpha)\right)$ and such that $\mathrm{C}^{\mathrm{j} 1}-\mathrm{Y}^{\mathrm{j} 1}>\mathrm{C}^{\mathrm{j}}(\alpha)-\mathrm{Y}^{\mathrm{j}}(\alpha)>\mathrm{C}^{\mathrm{j} 2}-\mathrm{Y}^{\mathrm{j} 2}$.

Therefore, $a \hat{\pi}(0<\hat{\pi}<1)$, must exist with $\hat{\pi}\left(C^{j 1}-Y^{j 1}\right)+(1-\hat{\pi})\left(C^{j 2}-Y^{j 2}\right)$ $=C^{j}(\alpha)-Y^{j}(\alpha)$. It also follows from Theorem II(v) that $V^{i}\left(C^{j 2}, Y^{j 2}\right)>$ $\mathrm{V}^{i}\left(C^{j}(\alpha), \mathrm{Y}^{j}(\alpha)\right)>\mathrm{V}^{i}\left(C^{j 1}, \mathrm{Y}^{j 1}\right)$ since the indifference curve of $j$ through $\left(C^{j}(\alpha), Y^{j}(\alpha)\right)$ lies between indifference curve of $i$ and the $45^{\circ}$ line through that bundle (see Figure 6). From Lemm I, there exists a transformation of $v^{i}$ such that $\hat{\pi} F\left(V^{i}\left(C^{j 1}, Y^{j 1}\right)\right)+(1-\hat{\pi}) F\left(V^{i}\left(C^{j 2}, Y^{j 2}\right)\right)<F\left(V^{i}\left(C^{j}(\alpha), Y^{j}(\alpha)\right)\right)=$ $F\left(V^{i}\left(C^{i}(\alpha), Y^{i}(\alpha)\right)\right.$. Since $V^{j}\left(C^{j 1}, Y^{j 1}\right)=V^{j}\left(C^{j 2}, Y^{j 2}\right)=V^{j}\left(C^{j}(\alpha), Y^{j}(\alpha)\right)$, $\hat{\pi} V^{j}\left(C^{j 1}, Y^{j 1}\right)+(1-\hat{\pi}) V^{j}\left(C^{j 2}, Y^{j 2}\right)>V^{j}\left(C^{i}(\alpha), Y^{i}(\alpha)\right)$ so the self-selection constraint for $j$ contimues to be satisfied. The self-selection constraint for $i$ is now satisfied with strict inequality. Hence, all constraints hold. If 
$1>\operatorname{MRS}^{j}\left(C^{j}(\alpha), Y^{j}(\alpha)\right)>\operatorname{MRS}^{i}\left(C^{j}(\alpha), Y^{j}(\alpha)\right)$, the bundles $\left(C^{j 1}, Y^{j 1}\right)$ and $\left(C^{j 2}\right.$, $\mathrm{Y}^{\mathrm{j} 2}$ ) can be chosen close enough to $\left(C^{j}(\alpha), Y^{j}(\alpha)\right)$ so that $1>\operatorname{MRS}^{j}\left(C^{j 1}, Y^{j 1}\right)$ and $I>\mathbb{R S S}^{j}\left(C^{j 2}, Y^{j 2}\right)$. Then consider the bundles $\left(C^{j 1}+\delta, Y^{j 1}+\delta\right)$ and $\left(C^{j 2}\right.$ $\left.+\delta, \mathrm{Y}^{\mathrm{j} 2}+\delta\right)$. These continue to satisfy resource balance. For small enough $\delta>0$, it will still follow that $\hat{\pi} F\left(V^{i}\left(C^{j 1}+\delta, Y^{j 1}+\delta\right)\right)+(1-\hat{\pi}) F\left(V^{i}\left(C^{j 2}+\right.\right.$ $\left.\left.\delta, Y^{j 2}+\delta\right)\right)<F\left(V^{i}\left(C^{i}(\alpha), Y^{i}(\alpha)\right)\right.$ so $i^{\prime}$ s self-selection constraint still holds. Since $1>M^{j} S^{j}$ at both bundles, $\mathrm{V}^{j}\left(C^{j}+\delta, \mathrm{Y}^{j}+\delta\right)>\mathrm{V}^{j}\left(C^{j 1}, \mathrm{Y}^{j 1}\right)$ and $\mathrm{V}^{\mathrm{j}}\left(\mathrm{C}^{\mathrm{j} 2}+\delta, \mathrm{Y}^{\mathrm{j} 2}+\delta\right)>\mathrm{V}^{\mathrm{j}}\left(\mathrm{C}^{\mathrm{j} 2}, \mathrm{Y}^{\mathrm{j} 2}\right)$. Hence, the lottery $\left(\left(\mathrm{C}^{\mathrm{j} 1}+\delta, \mathrm{Y}^{\mathrm{j} 1}+\delta\right)\right.$, $\left.\left(C^{j 2}+\delta, Y^{j 2}+\delta\right), \hat{\pi}\right)$ is feasible, raises $j^{\prime} s$ welfare and thus improves upon the nonrandam solution $\left(C^{j}(\alpha), Y^{j}(\alpha)\right)$. If $1<\operatorname{MRS}^{j}\left(C^{j}(\alpha), Y^{j}(\alpha)\right)<\mathbb{M R S}^{i}\left(C^{j}(\alpha)\right.$, $\left.\mathrm{Y}^{\mathrm{j}}(\alpha)\right)$ a similar proof follows with $\left(C^{j 1}-\delta, \mathrm{Y}^{j 1}-\delta\right)$ and $\left(\mathrm{C}^{\mathrm{j} 2}-\delta, \mathrm{Y}^{\mathrm{j} 2}-\delta\right)$ forming the lottery improving on $\left(C^{j}(\alpha), Y^{j}(\alpha)\right)$ Q.E.D.

PROOF OF THEOREM VI: From Theorem IV, $\lambda_{a}>0$ implies $\lambda_{b}=0$ and so it is not desirable to randomize A's tax schedule. Furthermore, the optimal randomization to offer $B$ need involve at most three tax schedules. This result carries over to finding lotteries which improve on the nomrandom solution to (PI) even if the optimal lottery is not found. That is, if a lottery over $k>3$ bundles is better than the nonrandom solution, a lottery over just 3 bundles must exist which also does better. Hence, we can restrict the analysis to lotteries $\left(\pi_{h}, c^{b h}, Y^{b h}\right), h=1,2,3$, where $\left[\pi_{h}=1\right.$. Let $\left(C^{a}, Y^{a}, C^{b}, Y^{b}\right)$ denote the nomrandam solution to (PI).

A lottery exists which improves upon $\left(C^{a}, Y^{a}, c^{b}, Y^{b}\right)$ if, holding $\left(C^{a}, Y^{a}\right)$ fixed:

$$
\begin{aligned}
& V^{a}\left(c^{b}, Y^{b}\right) \geq \sum \pi_{h} V^{a}\left(c^{b h}, Y^{b h}\right) \\
& N_{a}\left(C^{a}-Y^{a}\right)+N_{b}\left[\pi_{h}\left(c^{b h}-Y^{b h}\right) \leq 0\right. \\
& \sum \pi_{h} v^{b}\left(c^{b h}, Y^{b h}\right) \geq V^{b}\left(c^{b}, Y^{b}\right)
\end{aligned}
$$


and at least one of (A1) to (A3) holds with strict inequality. (A1) and (A2) guarantee the lottery is feasible while (A3) says that B's expected utility does not decline. (Al) can be replaced by an equality since, if it held with strict inequality, a mean preserving shrink of the lottery would continue to satisfy (A2) and would raise $\left[\pi_{h} V^{b}\left(C^{b h}, Y^{b h}\right)\right.$ leaving (A3) satisfied. Since (AI) is assumed to hold with strict inequality, a small rise in $\sum \Pi_{h} V^{a}\left(C^{b h}, Y^{b h}\right)$ would not violate it. Of course, such a shrinkage would cause (AI) to hold with equality before all randomess was eliminated, else there would exist a nonrandom vector better than $\left(C^{a}, \mathrm{Y}^{\mathrm{a}}, \mathrm{C}^{\mathrm{b}}, \mathrm{Y}^{\mathrm{b}}\right)$, a contradiction. If (A2) holds with strict inequality, $C^{a}$ could be raised to get an improvement while, if (A3) holds with strict inequality, the improvement is direct. Since $\mathrm{N}_{a}\left(C^{a}-Y^{a}\right)+$ $\mathrm{N}_{\mathrm{b}}\left(\mathrm{C}^{\mathrm{b}}-\mathrm{Y}^{\mathrm{b}}\right)=0$, equation $(\mathrm{A} 2)$ can be rewritten as

$$
\left[\Pi_{h}\left(c^{b h}-Y^{b h}\right)-c^{b}+Y^{b} \leq 0\right.
$$

Consider any probability vector $\left(\Pi_{1}, \Pi_{2}, \Pi_{3}\right)$. A local randomization is a path $\left(C^{h}(t), Y^{h}(t)\right), h=1,2,3$ with $\left(C^{h}(0), Y^{h}(0)\right)=\left(C^{b}, Y^{b}\right)$, all $h$, and such that for $t>0$ at least two bundles with nonzero probabilities differ from each other. A local randomization is improving for this probability vector if a path exists with

$$
\begin{aligned}
& \sum \pi_{h} V^{a}\left(c^{h}(t), Y^{h}(t)\right)=V^{a}\left(c^{b}, Y^{b}\right) \\
& \sum \pi_{h}\left(Y^{h}(t)-c^{h}(t)\right) \geq Y^{b}-c^{b} \\
& \sum \pi_{h} V^{b}\left(c^{h}(t), Y^{h}(t)\right) \geq V^{b}\left(c^{b}, Y^{b}\right)
\end{aligned}
$$

Differentiating (A5)-(A7) with respect to $t$ around $t=0$ and recalling that $\operatorname{MRS}^{i}=-v_{y}^{i} / v_{c}^{i}$ yields : 


$$
\begin{aligned}
& {\left[\pi_{h}\left[\frac{d C^{h}(0)}{d t}-M_{R} S^{a}\left(C^{b}, Y^{b}\right) \frac{d Y^{h}(0)}{d t}\right]=0\right.} \\
& {\left[\pi_{h}\left[\frac{d Y^{h}(0)}{d t}-\frac{d C^{h}(0)}{d t}\right] \geq 0\right.} \\
& \sum \Pi_{h}\left[\frac{d C^{h}(0)}{d t}-M R S^{b}\left(C^{b}, Y^{b}\right) \frac{d Y^{h}(0)}{d t}\right] \geq 0
\end{aligned}
$$

Substituting (A8) into (A9) and (A10) yields:

$$
\begin{aligned}
& {\left[1-\operatorname{MRS}^{a}\left(C^{b}, Y^{b}\right)\right]\left[\Pi_{h} \frac{d Y^{h}(0)}{d t} \geq 0\right.} \\
& {\left[M R S^{a}\left(C^{b}, Y^{b}\right)-\operatorname{MRS}^{b}\left(C^{b}, Y^{b}\right)\right] \sum \Pi_{h} \frac{d Y^{h}(0)}{d t} \geq 0}
\end{aligned}
$$

From Theorem II (v), $1-\operatorname{MRS}^{a}\left(C^{b}, Y^{b}\right)$ and $\operatorname{MRS}^{a}\left(C^{b}, Y^{b}\right)-M^{b} S^{b}\left(C^{b}, Y^{b}\right)$ must have opposite signs so that (Al1) and (A12) can both hold if and only if $\sum \Pi_{h} \frac{d Y^{h}(0)}{d t}=0$ which from (A8) implies that $\sum \Pi_{h} \frac{d C^{h}(0)}{d t}=0$. Thus, the first order effects along an improving path must be zero. The gain to randomization must came from second order effects. If either the second derivatives of net resources or of B's expected utility are positive, then, since the first derivatives are zero at $t=0$, for $t>0$, for $t>0$ the first derivatives and hence the functions will become positive as required. These second derivatives at $t=0$ are:

$$
\begin{aligned}
& {\left[\pi_{h} s^{h a}+\sum \Pi_{h}\left[V_{c}^{a}\left(C^{b}, Y^{b}\right) \frac{d^{2} c^{h}(0)}{d t^{2}}+V_{y}^{a}\left(c^{b}, Y^{b}\right) \frac{d^{2} Y^{h}(0)}{d t^{2}}\right]=0\right.} \\
& {\left[\pi_{h}\left[\frac{d^{2} Y^{h}(0)}{d t^{2}}-\frac{d^{2} c^{h}(0)}{d t^{2}}\right] \geq 0\right.} \\
& {\left[\pi_{h} s^{b h}+\left[\Pi_{h}\left[V_{c}^{b}\left(c^{b}, Y^{b}\right) \frac{d^{2} c^{b}(0)}{d t^{2}}+V_{y}^{b}\left(c^{b}, y^{b}\right) \frac{d^{2} Y^{b}(0)}{d t^{2}}\right] \geq 0\right.\right.}
\end{aligned}
$$


where $S^{i h}=\left(\frac{d C^{h}(0)}{d t}\right)^{2} V_{c c}^{i}\left(C^{b}, Y^{b}\right)+2 \frac{d Y^{b}(0)}{d t} \frac{d C^{h}(0)}{d t} V_{c y}^{i}\left(C^{b}, Y^{b}\right)+\left(\frac{d Y^{h}(0)}{d t}\right)^{2}$ $\mathrm{V}_{\mathrm{yy}}^{\mathrm{i}}\left(\mathrm{C}^{\mathrm{b}}, \mathrm{Y}^{\mathrm{b}}\right)$. From the fact that the utility functions are strictly concave, for any $h$ with $d c^{h}(0) / d t$ or $d Y^{h}(0) / d t$ not zero, $s^{\text {ih }}$ must be negative. For convenience, the arguments of partials of $\mathrm{v}^{i}$ are deleted since all partials are evaluated at $\left(C^{b}, Y^{b}\right)$.

Substituting (A13) into (A14) and (A15) yields

$$
\begin{aligned}
& Z \equiv\left(1-M S^{a}\right)\left[\Pi_{h} \frac{d^{2} Y^{h}(0)}{d t^{2}}+\sum \Pi_{h} s^{a h} / V_{c}^{a} \geq 0\right. \\
& {\left[M R S^{a}-M S^{b}\right]\left[\Pi_{h} \frac{d^{2} Y^{n}(0)}{d t^{2}}+\sum \Pi_{h}\left[\left(S^{b h} / V_{c}^{b}\right)-\left(S^{a h} / V_{c}^{a}\right)\right] \geq 0\right.}
\end{aligned}
$$

Solving (Al6) for $\sum \pi_{h} \frac{d^{2} Y^{h}(0)}{d t^{2}}$ and substituting into (Al7) gives:

$$
\frac{\left(M_{R S}^{b}-1\right)}{\left(1-M R S^{a}\right)}\left(\sum \Pi_{h} S^{a h}\right) / V_{c}^{a}+\left(\sum \Pi_{h} S^{b h}\right) / V_{c}^{b} \geq \frac{\left(M R S^{b}-M R S^{a}\right)}{\left(1-M R S^{a}\right)} z
$$

From Theorem II(v), $1-\mathbb{R S}^{\mathrm{a}}, 1-\mathbb{R R}^{\mathrm{b}}$, and $\mathbb{M R S}^{\mathrm{b}}-\mathbb{R R S}^{\mathrm{a}}$ all have the same sign. Hence, (A18) can be rewritten as

$$
\frac{\sum \Pi_{h} S^{b h}}{v_{c}^{b}\left|1-M R S^{b}\right|}-\frac{\sum \Pi_{h} S^{a h}}{v_{c}^{a}\left|1-M R S^{a}\right|} \geq \frac{\left|M R S^{b}-M R S^{a}\right|}{\left|1-M R S^{a}\right|\left|1-M R S^{b}\right|} z \geq 0
$$

Given any $\left(\pi_{1}, \pi_{2}, \pi_{3}\right)$, a path $\left(c^{h}(t), Y^{h}(t)\right), h=1,2,3$, yields a local randomization which improves on the nonrandom solution to (PI) iff $\frac{\mathrm{dc}^{\mathrm{h}}(0)}{\mathrm{dt}}$, $\frac{d Y^{h}(0)}{d t}, \frac{d^{2} c^{h}(0)}{d t^{2}}$ and $\frac{d^{2} Y^{h}(0)}{d t^{2}}$ are such that $\sum \Pi_{h} \frac{d c^{h}(0)}{d t}=\sum \Pi_{h} \frac{d Y^{h}(0)}{d t}=0$ but, for same $h,\left(\frac{d C^{h}(0)}{d t}, \frac{d Y^{h}(0)}{d t}\right) \neq 0$, and (A15), (Al6), and (A19) hold with a strict inequality in (A16) or (A19). Note that since $\left(1-M_{R} S^{a}\right)=0$ and $d^{2} Y^{h}(0) / d t$ are otherwise unrestricted, for any $\left(d C^{h}(0) / d t, d Y^{h}(0) / d t\right), h=1,2,3$, 
$d^{2} Y^{h}(0) / d t^{2}, h=1,2,3$, can be chosen to make $\mathrm{Z}$ defined in (A16) take any value. Given this choice of $d^{2} Y^{h}(0) / d t^{2}, h=1,2,3, d^{2} c^{h}(0) / d t^{2}, h=1,2,3$, can always be chosen to make (A13) hold. It therefore follows that local randomization is desirable iff there exists a $\left(d C^{h}(0) / d t, d Y^{h}(0) / d t\right)$, $h=1,2,3$, such that

$$
\frac{\sum \pi_{h} s^{b h}}{V_{c}^{b}\left|1-M R S^{b}\right|}>\frac{\sum \pi_{h} s^{a h}}{V_{c}^{a}\left|1-M R S^{a}\right|}
$$

Necessity of (A20) follows directly from (A19). If (A20) holds, then, given (A16) $d^{2} Y^{h}(0) / d t^{2}$ can be chosen to make $Z$ small enough that (A19) holds. If (A20) holds, then for at least one $h, s^{b h} /\left(V_{c}^{b} \mid 1-M^{b} s^{b}\right)>$ $S^{a h} /\left(V_{c}^{a}\left|1-M R S^{a}\right|\right)$ must hold. For this $h$, set $X=\left(d c^{h}(0) / d t, d Y^{h}(0) / d t\right)$ and necessity is shown. To show sufficiency, let $x^{h}=\left(x_{1}^{h}, x_{2}^{h}\right)=\left(d C^{n}(0) / d t\right.$, $\left.d Y^{h}(0) / d t\right), h=1,2,3$ and assume there exists a $Y=\left(Y_{1}, Y_{2}\right)$ such that $\left(\mathrm{YH}^{\mathrm{b}} \mathrm{Y}^{\mathrm{t}}\right) /\left(\mathrm{V}_{\mathrm{c}}^{\mathrm{b}}\left|1-\mathrm{MRS}^{\mathrm{b}}\right|\right)>\left(\mathrm{YH}^{\mathrm{a}_{\mathrm{Y}}} \mathrm{t}^{\mathrm{t}}\right) /\left(\mathrm{V}_{\mathrm{c}}^{\mathrm{b}}\left|1-\mathrm{MRS}^{\mathrm{b}}\right|\right)$. Given $\Pi_{1}, \Pi_{2}$, and $\Pi_{3}$, some allowable $X^{h}, h=1,2,3$ will exist that is equivalent to $\left(Y_{1}, Y_{2}\right)$ if the following five conditions are satisfied:

$$
\begin{aligned}
& \pi_{1} x_{1}^{1}+\pi_{2} x_{1}^{2}+\pi_{3} x_{1}^{3}=0 \\
& \pi_{1} x_{2}^{1}+\pi_{2} x_{2}^{2}+\pi_{3} x_{2}^{3}=0 \\
& \pi_{1}\left(x_{1}^{1}\right)^{2}+\pi_{2}\left(x_{1}^{2}\right)^{2}+\pi_{3}\left(x_{1}^{3}\right)^{2}=y_{1}^{2} \\
& \pi_{1}\left(x_{2}^{1}\right)^{2}+\pi_{2}\left(x_{2}^{2}\right)^{2}+\pi_{3}\left(x_{2}^{3}\right)^{2}=y_{2}^{2} \\
& \pi_{1} x_{1}^{1} x_{2}^{1}+\pi_{2} x_{1}^{2} x_{2}^{2}+\pi_{3} x_{1}^{3} x_{2}^{3}=Y_{1} Y_{2}
\end{aligned}
$$

Conditions (A21) and (A22) guarantee that $\left[\pi_{h}\left(d C^{h}(0) / d t\right)=\sum \pi_{h}\left(d Y^{h}(0) / d t\right)=0\right.$ while (A23)-(A25) guarantee that $\sum \pi_{h}\left(X^{h} H^{b}\left(X^{h}\right)^{t}\right)=Y^{b} Y^{t}$ and that 
$\sum \pi_{h}\left(X^{h} H^{a}\left(X^{h}\right)^{t}\right)=Y H^{a} Y^{t}$. Given the assumptions on $Y$, any solution to (A21)(A25) would satisfy (A20). Since at least two of the $\pi_{h}$ must be positive, assume without loss of generality that $\pi_{1}>0$ and $\pi_{2}>0$. Consider $\mathrm{x}_{1}^{3}=\mathrm{x}_{2}^{3}=0, \mathrm{x}_{1}^{2}=-\left(\pi_{1} / \pi_{2}\right) \mathrm{x}_{1}^{1}=\mathrm{Y}_{1}\left[\pi_{1} /\left(\pi_{2}\left(\pi_{1}+\Pi_{2}\right)\right)\right]^{\frac{1}{2}}$, and $\mathrm{x}_{2}^{2}=-\left(\pi_{1} / \pi_{2}\right) \mathrm{x}_{2}^{1}=$ $\mathrm{Y}_{2}\left[\pi_{1} /\left(\pi_{2}\left(\pi_{1}+\pi_{2}\right)\right)\right]^{\frac{1}{2}}$. Substituting these values shows that (A21)-(A25) are satisfied showing sufficiency.

PROOF OF COROLIARY II:

Let $Q\left(P_{a}, P_{b}\right)=\left|1-M R^{a}\right| \frac{q^{b} q^{t}}{V_{c}^{b}}-\left|1-M_{R} S^{b}\right| \frac{q^{a} q^{t}}{V_{c}^{a}}$. From Theorem III, local randomization is desirable at some $P_{a}$ and $P_{b}$, if $Q\left(P_{a}, P_{b}\right)>0$. At $P_{a}=P_{b}$, no redistribution is possible since their indifference maps are identical so $M_{R} S^{a}=M R S^{b}=1$. Hence $Q\left(P_{a}, P_{b}\right)=0$. Differentiating $Q$ with respect to $P_{a}$ around $\mathrm{P}_{\mathrm{a}}=\mathrm{P}_{\mathrm{b}}$ yields

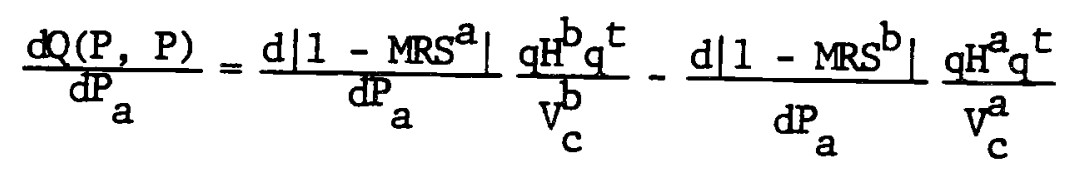

Since $V^{a}=F\left(V^{b}\right), V_{c}^{a}=F^{\prime} V_{c}^{b}, V_{c c}^{a}=F^{\prime} V_{c c}^{b}+F^{\prime \prime}\left(V_{c}^{b}\right)^{2}, V_{y y}^{a}=F^{\prime} V_{y y}^{b}+F^{\prime \prime}\left(V_{y}^{b}\right)^{2}$, and $v_{c y}^{a}=F^{\prime} V_{c y}^{b}+F^{\prime} v_{c}^{b} v_{y}^{b}$. When $P_{a}=P_{b}$, substituting these into $\left(q H^{a} q^{t}\right) / V_{c}^{a}$ yields:

$$
\frac{\mathrm{qH}^{\mathrm{a}} \mathrm{q}^{\mathrm{t}}}{\mathrm{v}_{\mathrm{c}}^{\mathrm{a}}}=\frac{\mathrm{qH}^{\mathrm{b}} \mathrm{q}^{\mathrm{t}}}{\mathrm{v}_{\mathrm{c}}^{\mathrm{b}}}+\frac{\mathrm{v}_{\mathrm{c}^{\mathrm{F}^{\prime \prime}}}^{\mathrm{b}^{\prime}}}{\mathrm{F}^{\prime}}\left(\mathrm{q}_{1}-\mathrm{q}_{2}\right)^{2}
$$

Substituting (A27) into (A26) yields

$$
\begin{aligned}
& \frac{d Q(P, P)}{d P_{a}}=\frac{q^{b} q^{t}}{V_{c}^{b}}\left[\frac{d\left|1-M R S^{a}\right|}{d P_{a}}-\frac{d\left|1-M R S^{b}\right|}{d P_{a}}\right] \\
& -\frac{V_{F^{\prime \prime}}^{b_{F^{\prime}}}}{F^{\prime}}\left(q_{1}-q_{2}\right)^{2} \frac{d\left|1-M R S^{a}\right|}{d P_{a}}
\end{aligned}
$$

